\title{
Supporting Information \\ Design of Radiolabeled Analogs of Minigastrin by Multiple Amide-to-Triazole Substitutions
}

Nathalie M. Grob, ${ }^{[a]}$ Sarah Schmid, ${ }^{[a]}$ Roger Schibli, ${ }^{[a, b]}$ Martin Behe, ${ }^{*[b]}$ and Thomas L. Mindt $*[c, d, e]$

${ }^{a}$ Department of Chemistry and Applied Biosciences, ETH Zurich, 8093 Zürich (Switzerland)

${ }^{\mathrm{b}}$ Center for Radiopharmaceutical Sciences, Division of Biology and Chemistry, Paul Scherrer Institute, 5232 Villigen (Switzerland)

${ }^{\mathrm{c}}$ Ludwig Boltzmann Institute Applied Diagnostics, General Hospital of Vienna, 1090 Vienna (Austria)

${ }^{\mathrm{d}}$ Department of Inorganic Chemistry, Faculty of Chemistry, University of Vienna, 1090 Vienna (Austria)

e Department of Biomedical Imaging and Image Guided Therapy, Medical University of Vienna, 1090 Vienna (Austria)

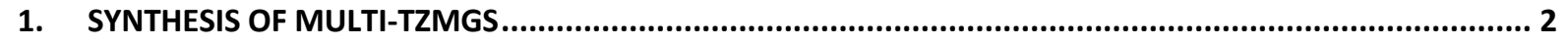

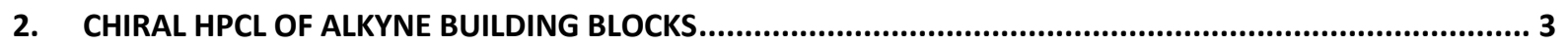

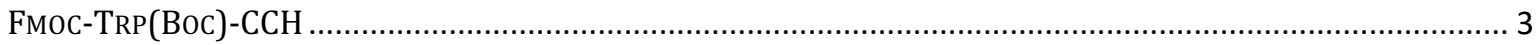

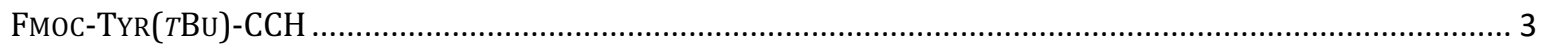

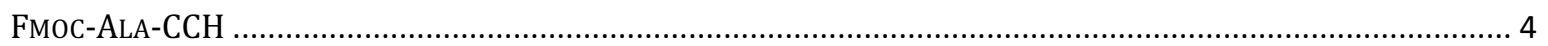

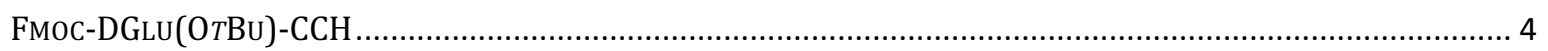

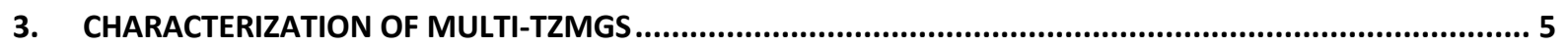

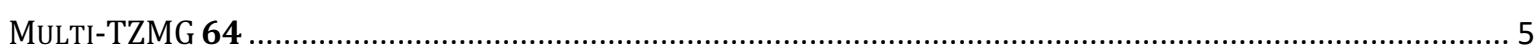

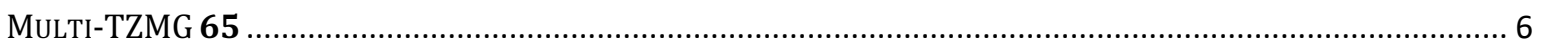

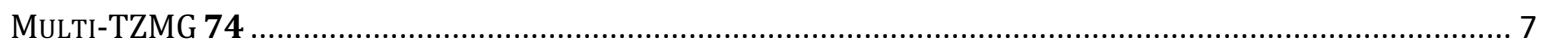

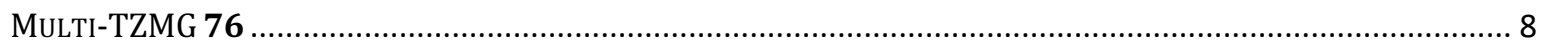

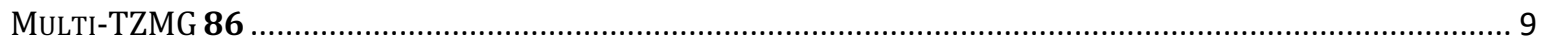

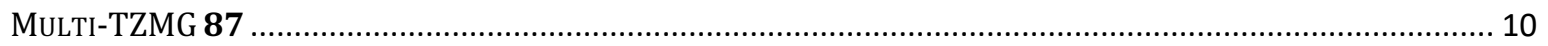

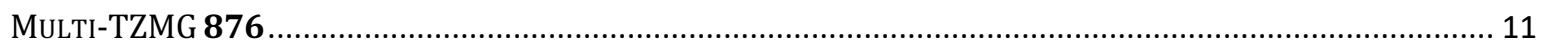

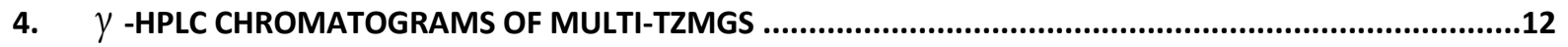

5. COMPARISON OF MONO- AND MULTI-TZMGS IN VITRO ................................................................14

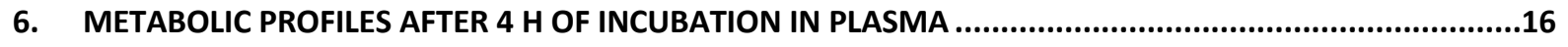

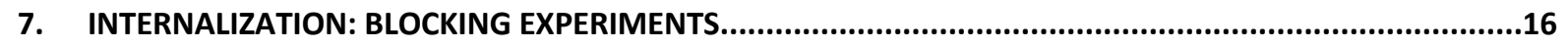

8. BIODISTRIBUTION: TABLES OF ALL ORGANS AND BLOCKING EXPERIMENTS ...................................17

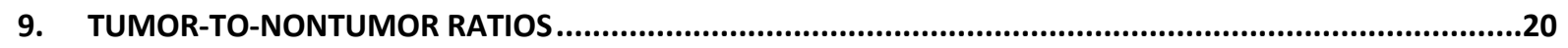

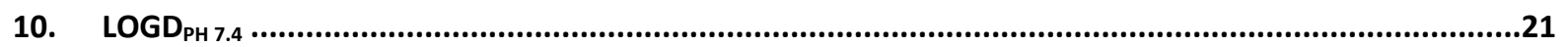

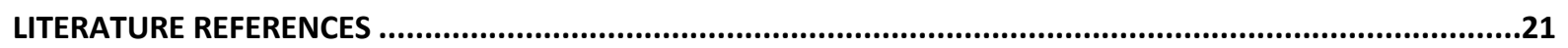




\section{Synthesis of Multi-TZMGs}

The building blocks for CuAAC and triazolopeptides have been prepared by adapted procedures reported in literature by Mindt and coworkers.1-3. Figure adapted from Grob et al.. ${ }^{3}$
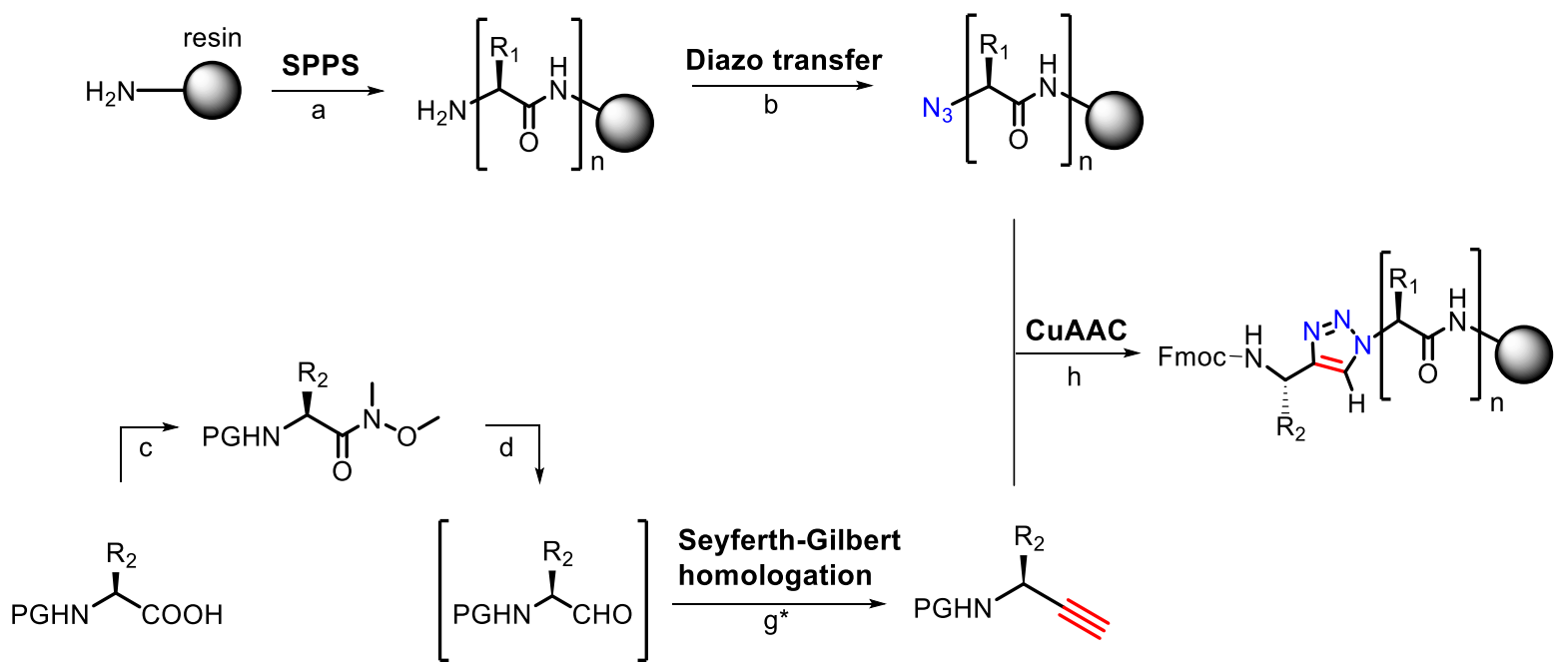<smiles>[R2][C@H](CO)N[PbH]</smiles>

Scheme S1: Overview of synthetic strategy. $P G=B o c$ or Fmoc protecting group; $R_{1} / R_{2}=$ amino acid specific side chain. a) i) amino acids, HATU, DIPEA ii) piperidine; b) imidazol-1-sulfonyl azide HCl, DIPEA; c) BOP, DIPEA, $N, O$ dimethylhydroxylamine; d) DIBAl-H; e) i) NMM, isobutyl chloroformate ii) $\mathrm{NaBH}_{4}$; f) i) DMSO, oxalyl chloride ii) DIPEA; g) $\mathrm{MeOH}, \mathrm{K}_{2} \mathrm{CO}_{3}$, dimethyl-(1-diazo-2-oxopropyl)phosphonate; ${ }^{*}$ if $\mathrm{PG}=$ Boc: i) TFA ii) Fmoc-OSu, DIPEA; h) tetrakis(MeCN)Cu(I) $\mathrm{PF}_{6}$, TBTA, DIPEA 


\section{Chiral HPCL of Alkyne Building Blocks}

Fmoc-Trp(Boc)-CCH

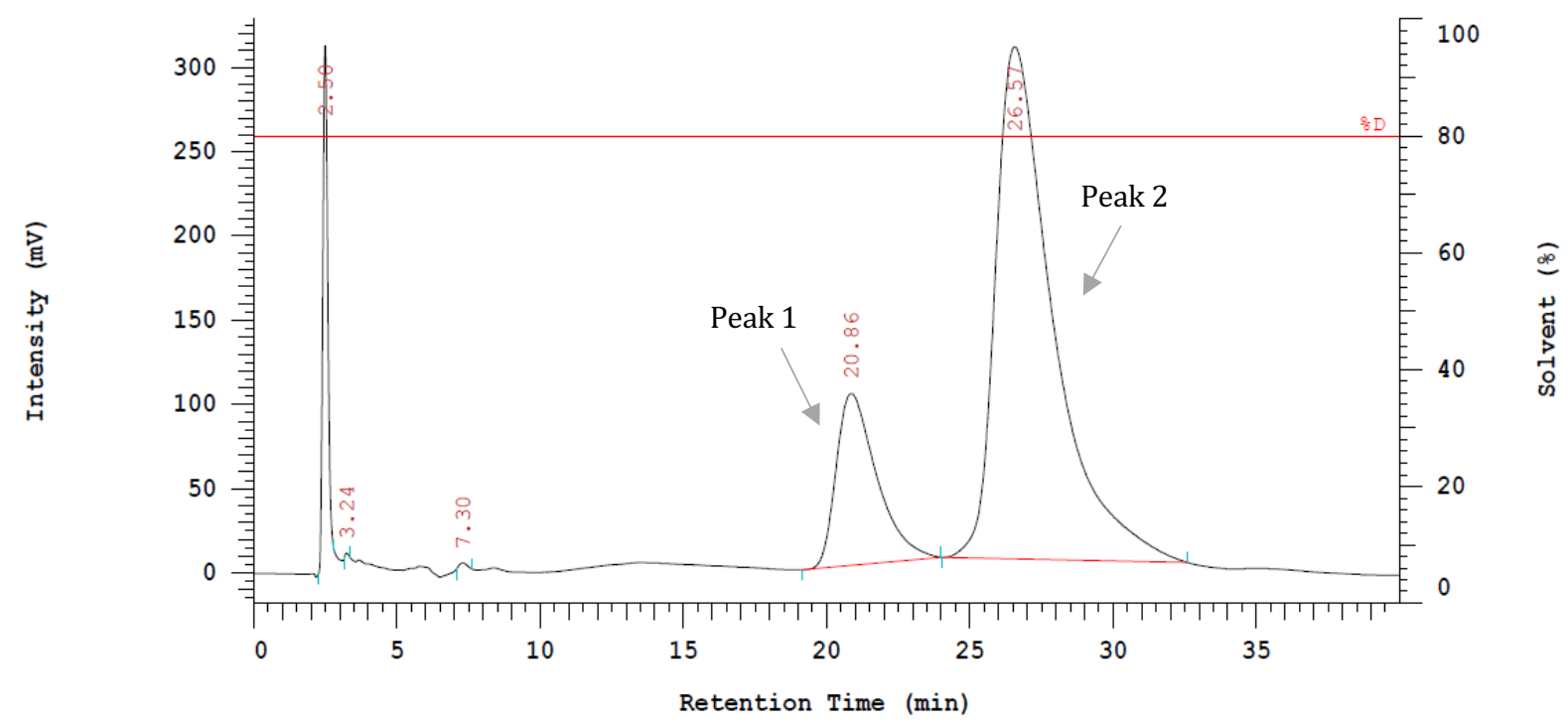

Figure S1: Chiral HPLC chromatogram of partially racemized Fmoc-Trp(Boc)-CCH: Fmoc-DTrp(Boc)-CCH (Peak 1, $\mathrm{t}_{\mathrm{r}}=$ $20.86 \mathrm{~min}, 19 \%$ ), Fmoc-LTrp(Boc)-CCH (Peak 2, $\mathrm{t}_{\mathrm{r}}=26.57 \mathrm{~min}, 81 \%$ ) separated by 20\% isopropyl alcohol in hexane over $40 \mathrm{~min}$.

\section{Fmoc-Tyr $(t \mathrm{Bu})-\mathrm{CCH}$}

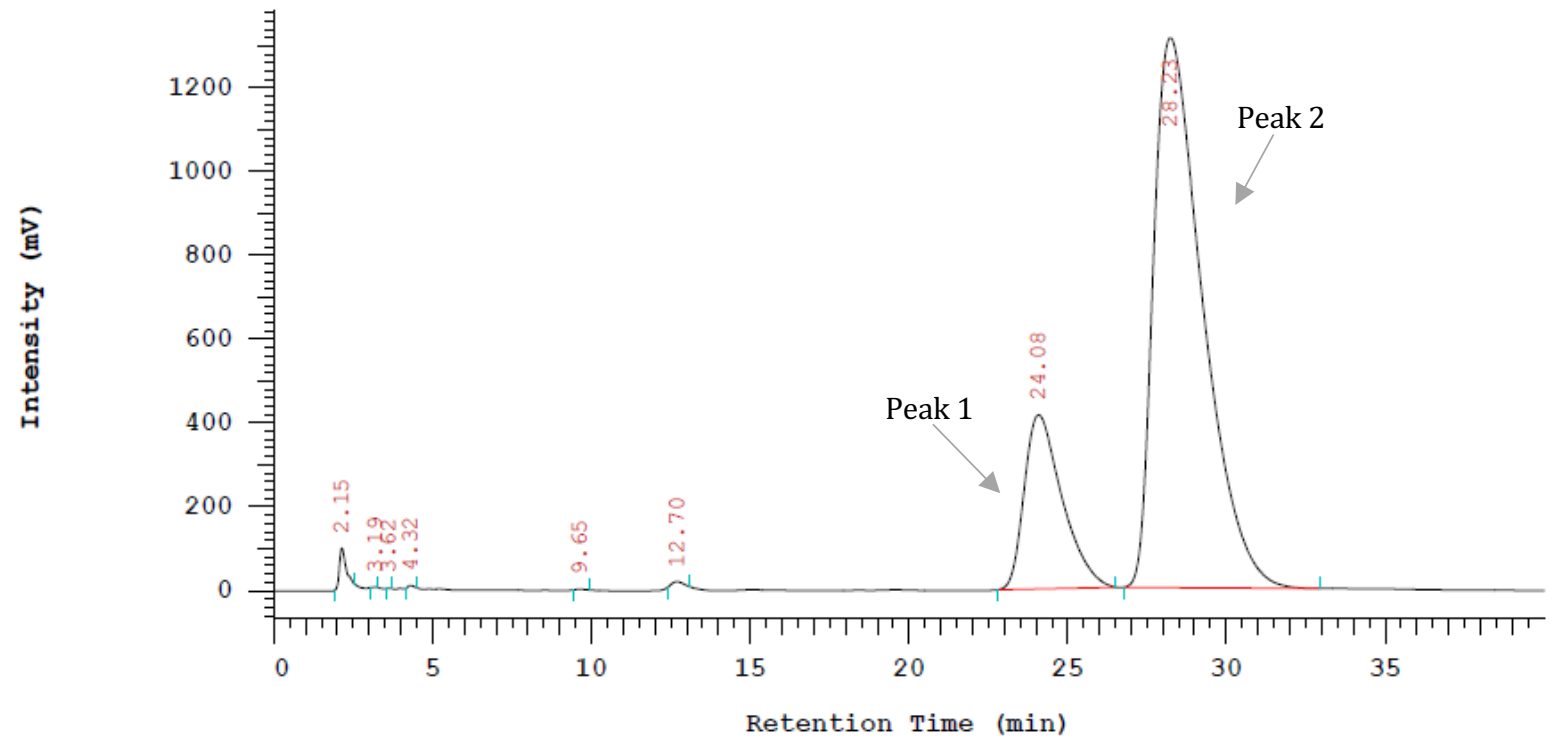

Figure S2: Chiral HPLC chromatogram of partially racemized Fmoc-Tyr $(t \mathrm{Bu})-\mathrm{CCH}$ : Fmoc-DTyr $(t \mathrm{Bu})-\mathrm{CCH}\left(\mathrm{Peak} 1, \mathrm{tr}_{\mathrm{r}}=\right.$ $24.08 \mathrm{~min}, 20 \%$ ), Fmoc-LTyr( $t \mathrm{Bu})-\mathrm{CCH}$ (Peak 2, $\mathrm{r}_{\mathrm{r}}=28.23 \mathrm{~min}, 80 \%$ ) separated by 7\% isopropyl alcohol in hexane over $40 \mathrm{~min}$. 


\section{Fmoc-Ala-CCH}

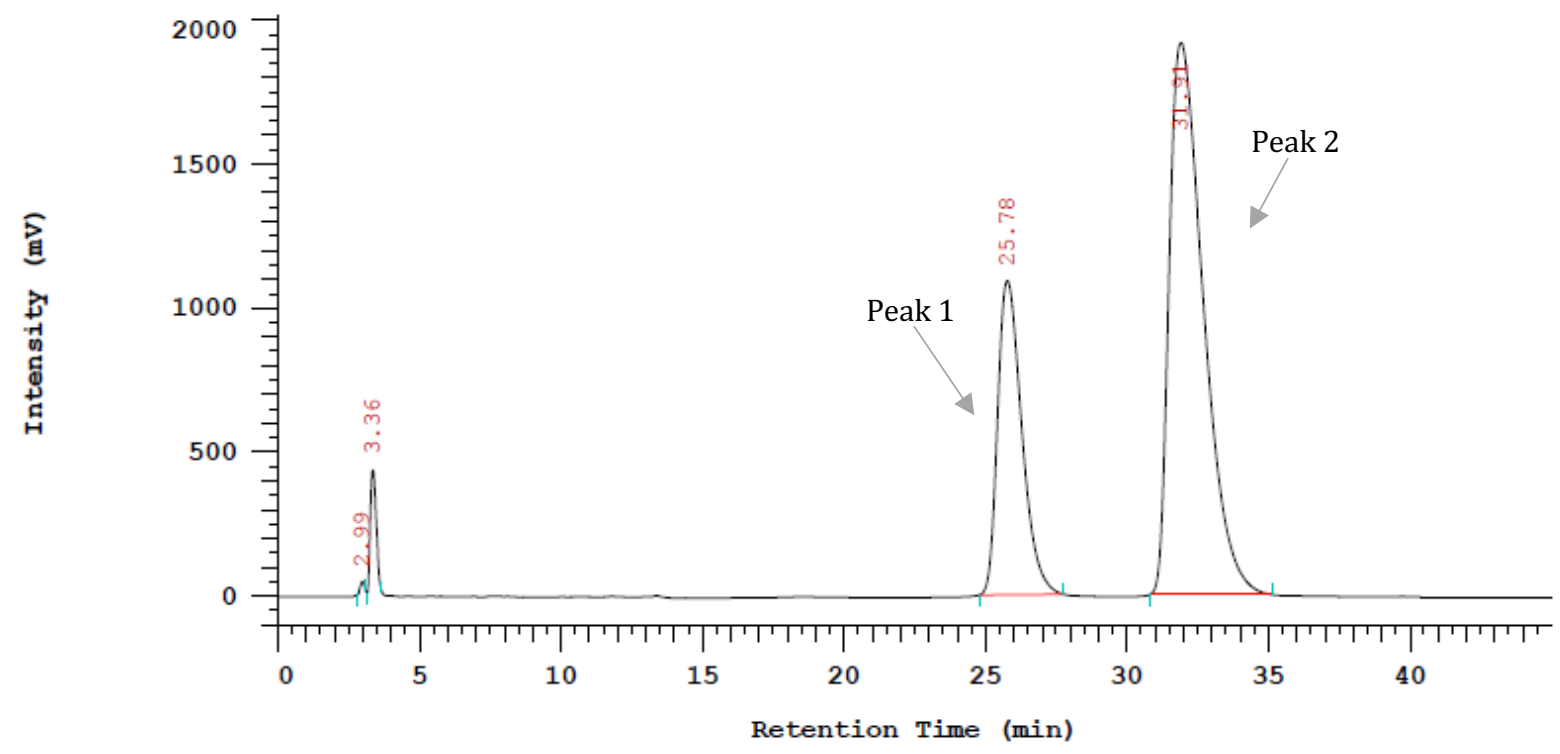

Figure S3: Chiral HPLC chromatogram of partially racemized Fmoc-Ala-CCH: Fmoc-DAla-CCH (Peak 1, $\mathrm{t}_{\mathrm{r}}=25.78 \mathrm{~min}$, 28\%), Fmoc-LAla-CCH (Peak 2, $\mathrm{t}_{\mathrm{r}}=31.91 \mathrm{~min}, 72 \%$ ) separated by 5\% isopropyl alcohol in hexane over $45 \mathrm{~min}$.

\section{Fmoc-DGlu(OtBu)-CCH}

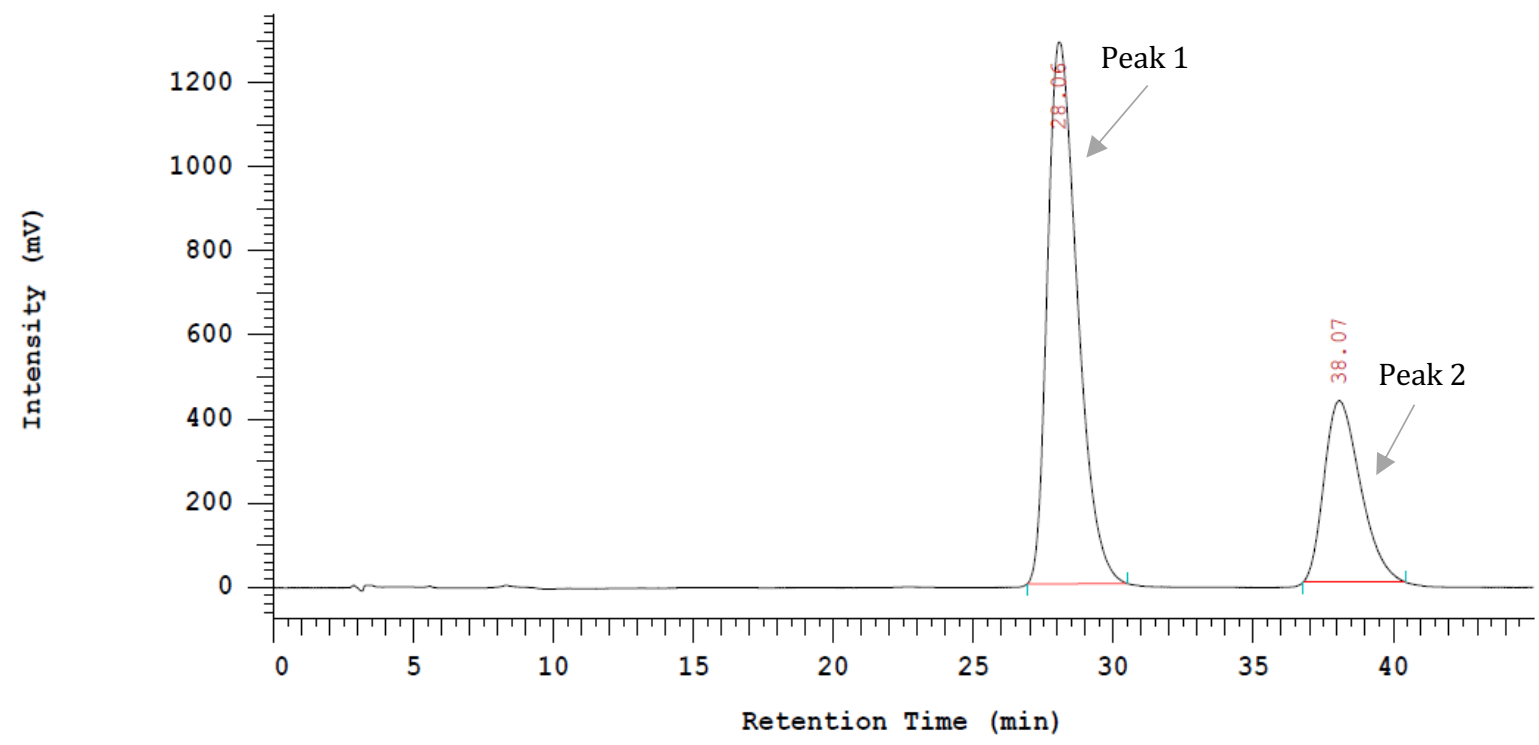

Figure S4: Chiral HPLC chromatogram of partially racemized Fmoc-DGlu(OtBu)-CCH: Fmoc-DGlu(OtBu)-CCH (Peak 1, $\left.\mathrm{t}_{\mathrm{r}}=28.06 \mathrm{~min}, 72 \%\right)$, Fmoc-LGlu(OtBu)-CCH (Peak 2, $\mathrm{t}_{\mathrm{r}}=38.07 \mathrm{~min}, 28 \%$ ) separated by 8\% isopropyl alcohol in hexane over $40 \mathrm{~min}$. 


\section{Characterization of Multi-TZMGs}

\section{Multi-TZMG 64}<smiles>CCCC[C@H](C(=O)N[C@@H](CC(=O)O)C(=O)N[C@@H](Cc1ccccc1)C(N)=O)n1cc(C(Cc2c[nH]c3ccccc23)NC(=O)Cn2cc([C@@H](Cc3ccc(O)cc3)NC(=O)[C@H](C)NC(=O)[C@H](CCC(=O)O)NC(=O)CN3CCN(CC(=O)O)CCN(CC(=O)O)CCN(CC(=O)O)CC3)nn2)nn1</smiles>

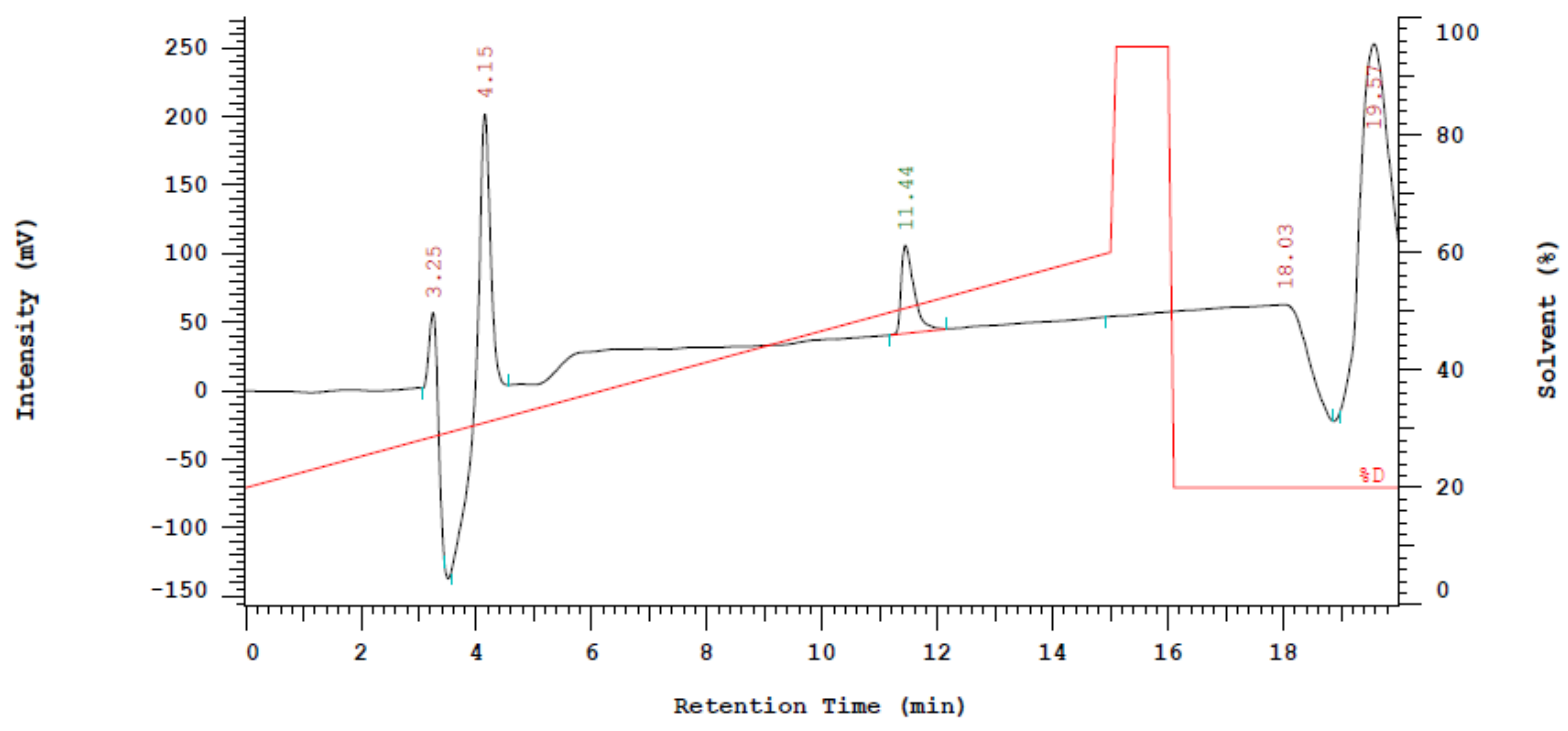

Figure S5: analytical HPLC chromatogram of purified Multi-TZMG 64, $\mathrm{t}_{\mathrm{r}}=11.44 \mathrm{~min}, 20-60 \% \mathrm{~A}$ in B over $15 \mathrm{~min}$.

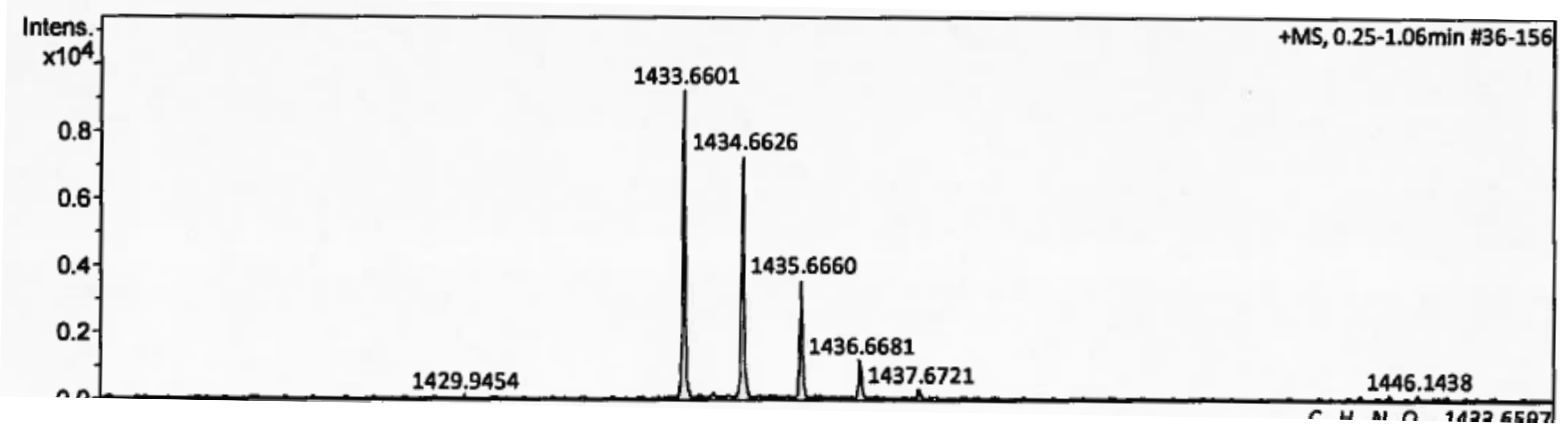

Figure S6: ESI HR-MS of purified Multi-TZMG 64. 


\section{Multi-TZMG 65}<smiles>CCCC[C@H](NC(=O)[C@@H](Cc1c[nH]c2ccccc12)n1cc(Cn2cc([C@@H](Cc3ccc(O)cc3)NC(=O)[C@H](C)NC(=O)[C@H](CCC(=O)O)NC(=O)CN3CCN(CC(=O)O)CCN(CC(=O)O)CCN(CC(=O)O)CC3)nn2)nn1)C(=O)N[C@@H](CC(=O)O)C(=O)N[C@@H](Cc1ccccc1)C(N)=O</smiles>

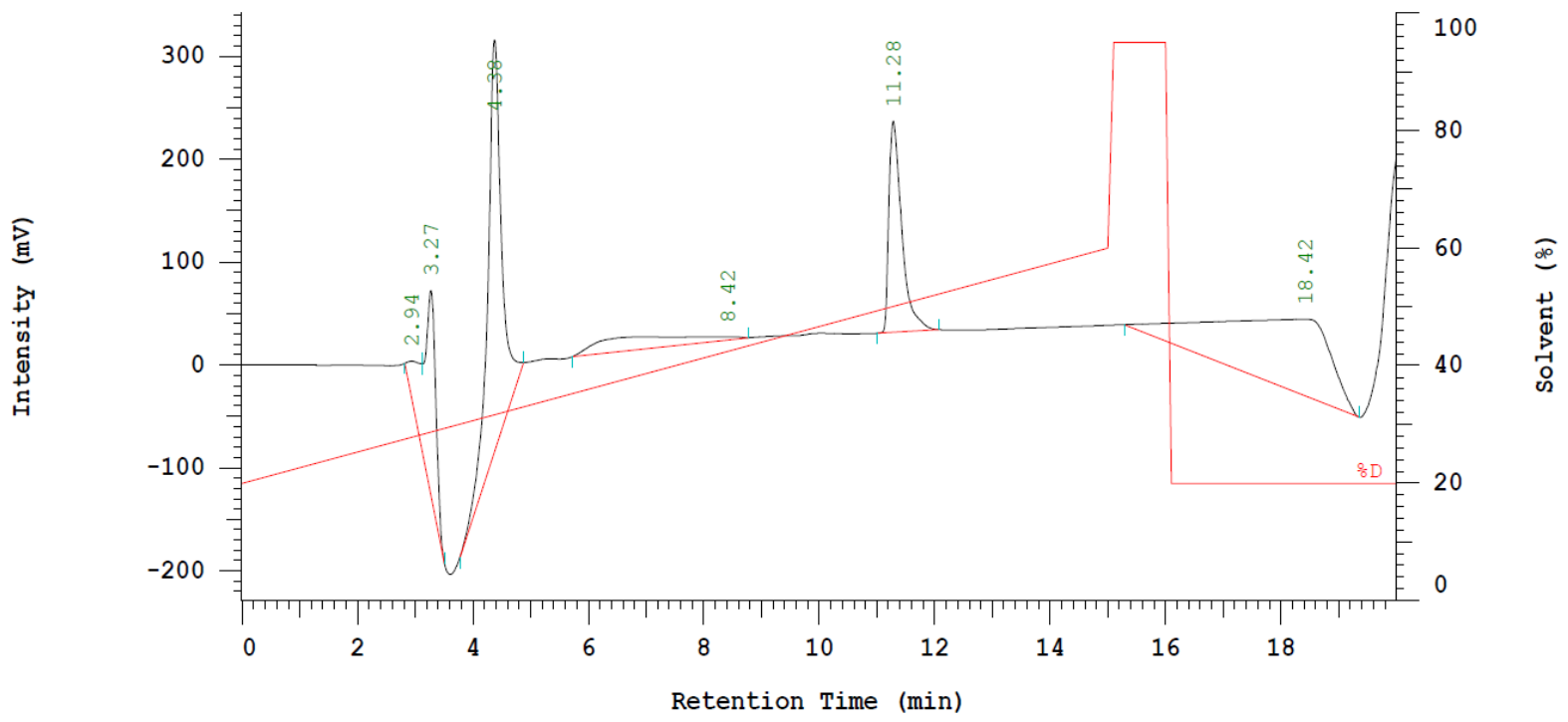

Figure S7: analytical HPLC chromatogram of purified Multi-TZMG 65, $\mathrm{t}_{\mathrm{r}}=11.28 \mathrm{~min}, 20-60 \% \mathrm{~A}$ in B over $15 \mathrm{~min}$.

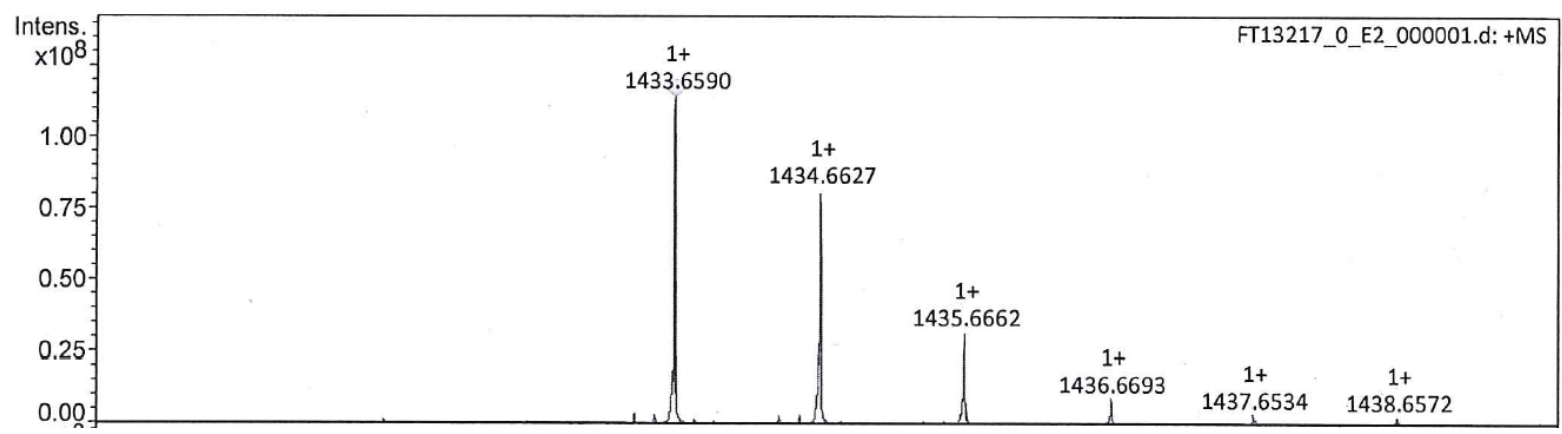

Figure S8: ESI HR-MS of purified Multi-TZMG 65. 
Multi-TZMG 74<smiles>CCCC[C@H](C(=O)N[C@@H](CC(=O)O)C(=O)N[C@@H](Cc1ccccc1)C(N)=O)n1cc([C@@H](Cc2c[nH]c3ccccc23)NC(=O)CNC(=O)[C@@H](Cc2ccc(O)cc2)n2cc([C@@H](C)NC(=O)[C@H](CCC(=O)O)NC(=O)CN3CCN(CC(=O)O)CCN(CC(=O)O)CCN(CC(=O)O)CC3)nn2)nn1</smiles>

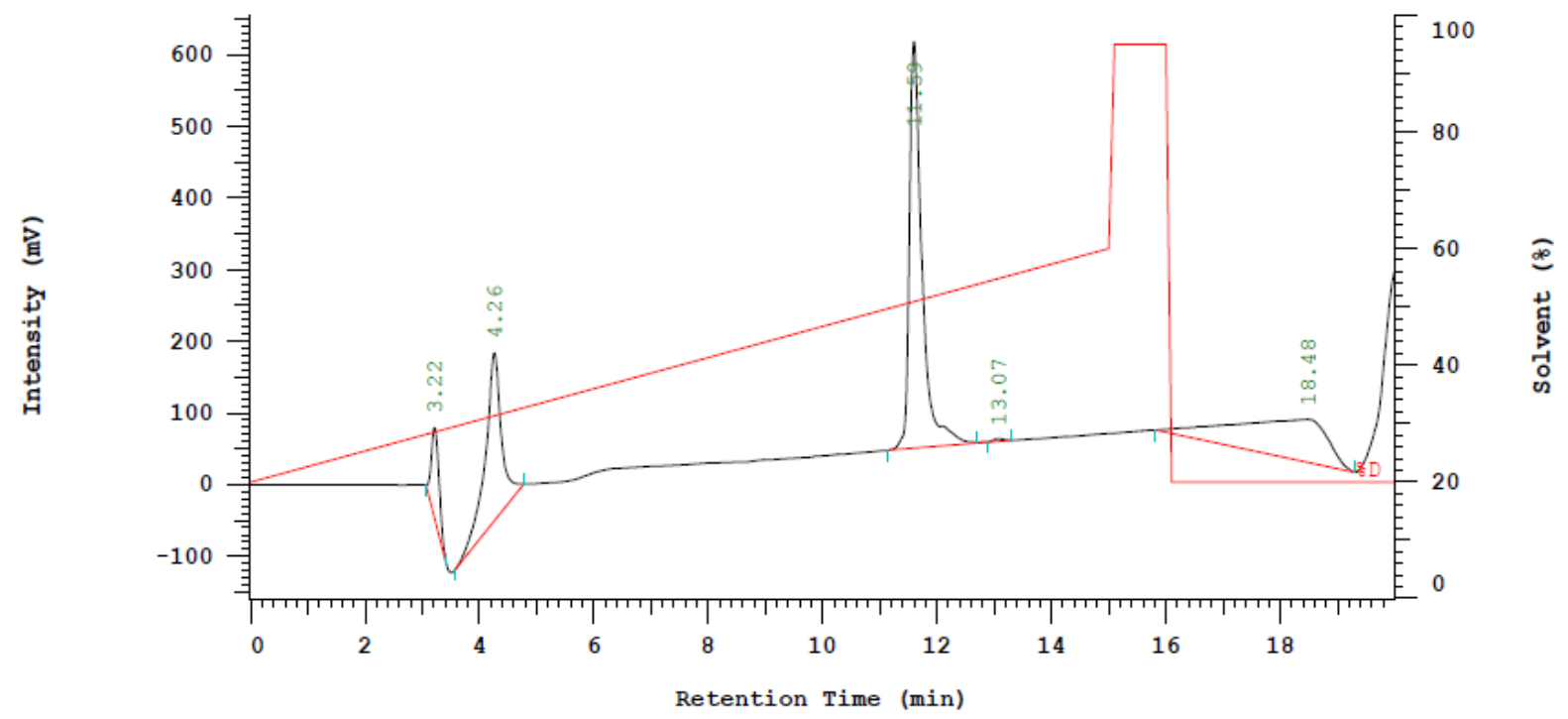

Figure S9: analytical HPLC chromatogram of purified Multi-TZMG 74, $\mathrm{t}_{\mathrm{r}}=11.59 \mathrm{~min}, 20-60 \%$ A in B over 15 min.

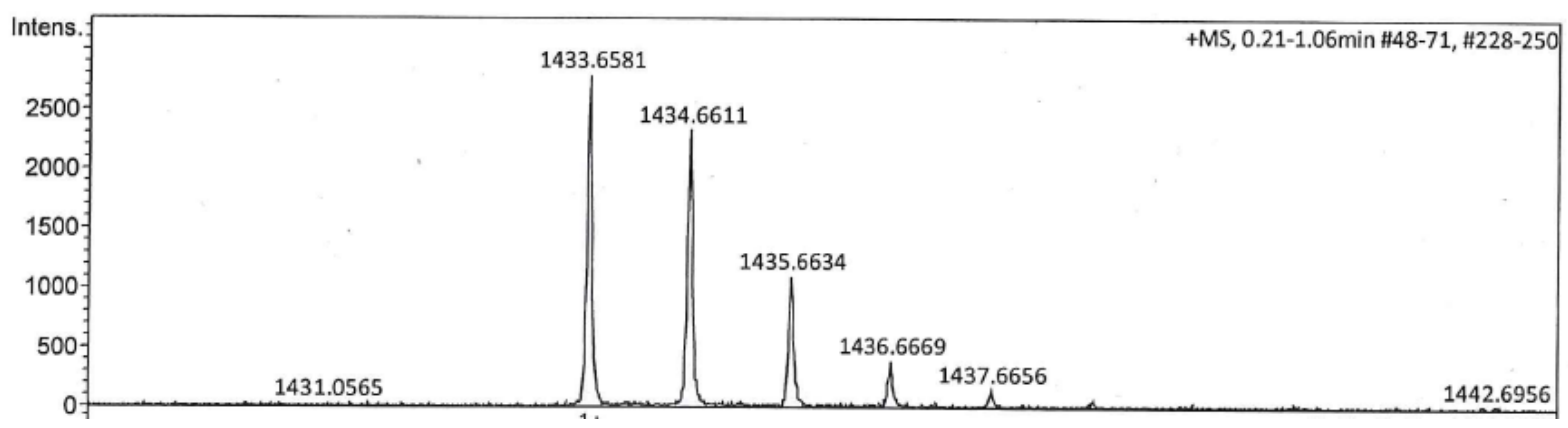

Figure S10: ESI HR-MS of purified Multi-TZMG 74. 
Multi-TZMG 76<smiles>CCCC[C@H](NC(=O)[C@H](Cc1c[nH]c2ccccc12)NC(=O)Cn1cc([C@H](Cc2ccc(O)cc2)n2cc([C@@H](C)NC(=O)[C@H](CCC(=O)O)NC(=O)CN3CCN(CC(=O)O)CCN(CC(=O)O)CCN(CC(=O)O)CC3)nn2)nn1)C(=O)N[C@@H](CC(=O)O)C(=O)N[C@@H](Cc1ccccc1)C(N)=O</smiles>

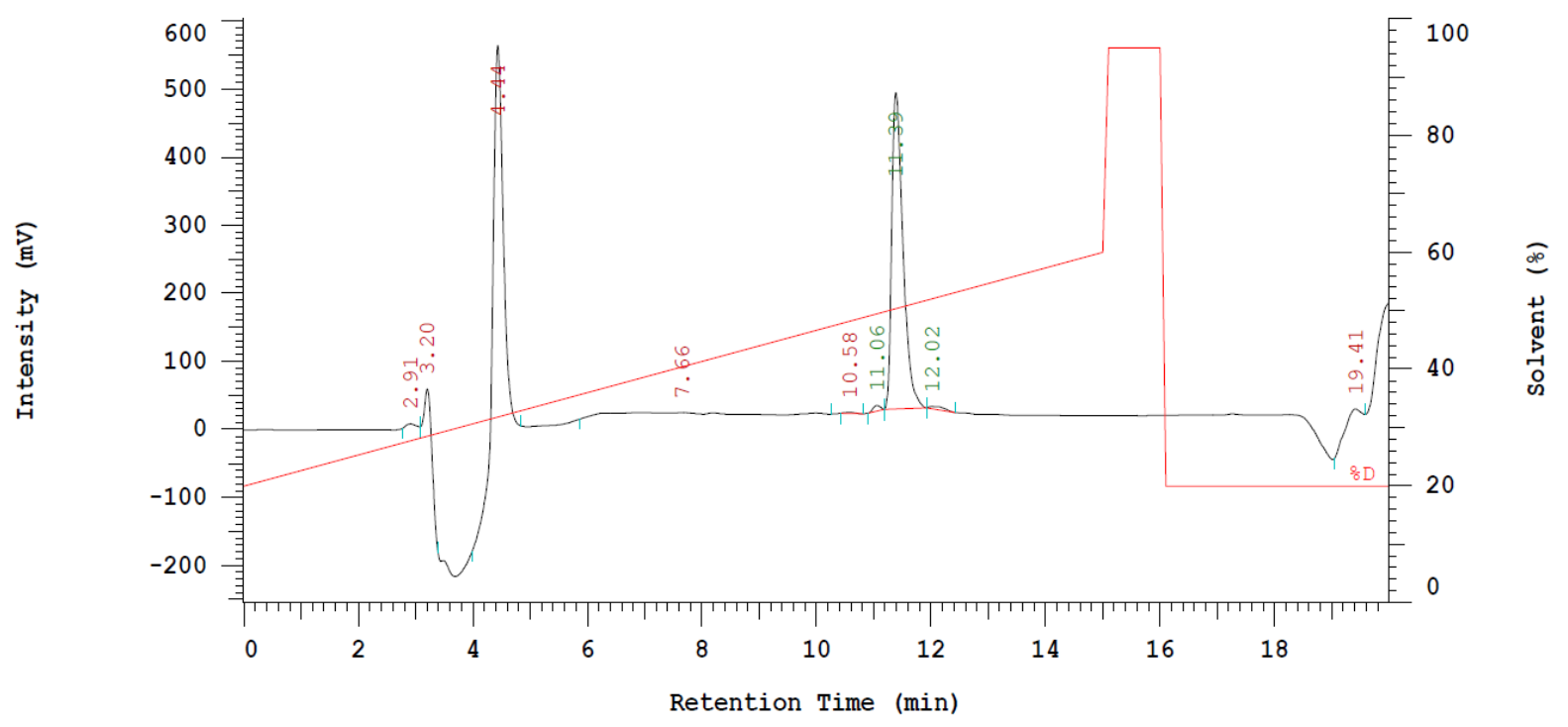

Figure S11: analytical HPLC chromatogram of purified Multi-TZMG 76, $\mathrm{t}_{\mathrm{r}}=11.39 \mathrm{~min}, 20-60 \%$ A in B over 15 min.

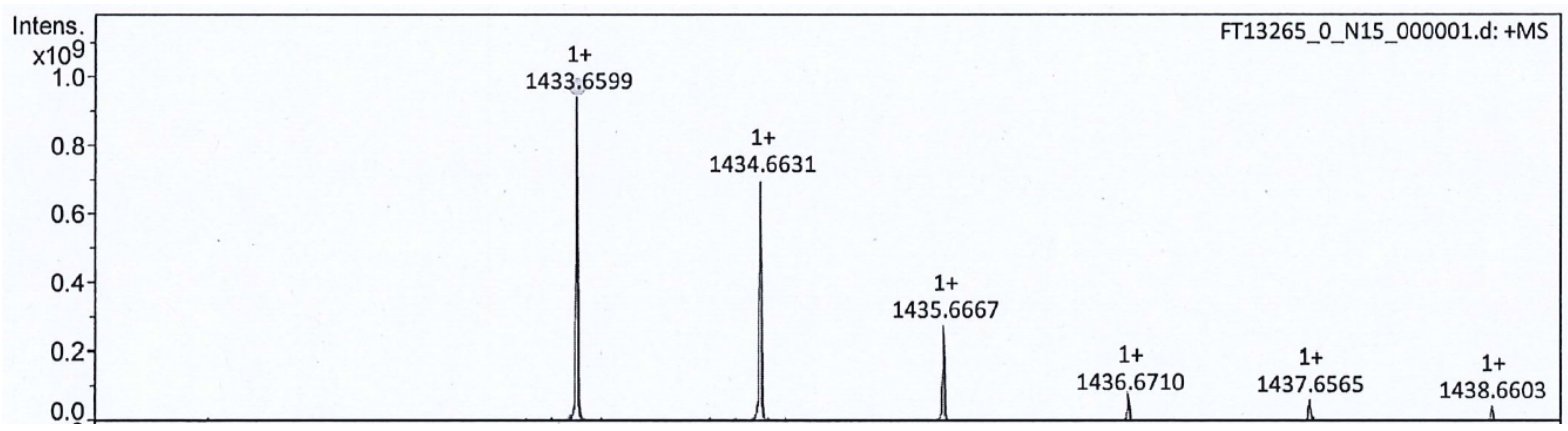

Figure S12: ESI HR-MS of purified Multi-TZMG 76. 
Multi-TZMG 86<smiles>CCCC[C@H](NC(=O)[C@H](Cc1c[nH]c2ccccc12)NC(=O)Cn1cc([C@H](Cc2ccc(O)cc2)NC(=O)[C@H](C)n2cc([C@@H](CCC(=O)O)NC(=O)CN3CCN(CC(=O)O)CCN(CC(=O)O)CCN(CC(=O)O)CC3)nn2)nn1)C(=O)N[C@@H](CC(=O)O)C(=O)N[C@@H](Cc1ccccc1)C(N)=O</smiles>

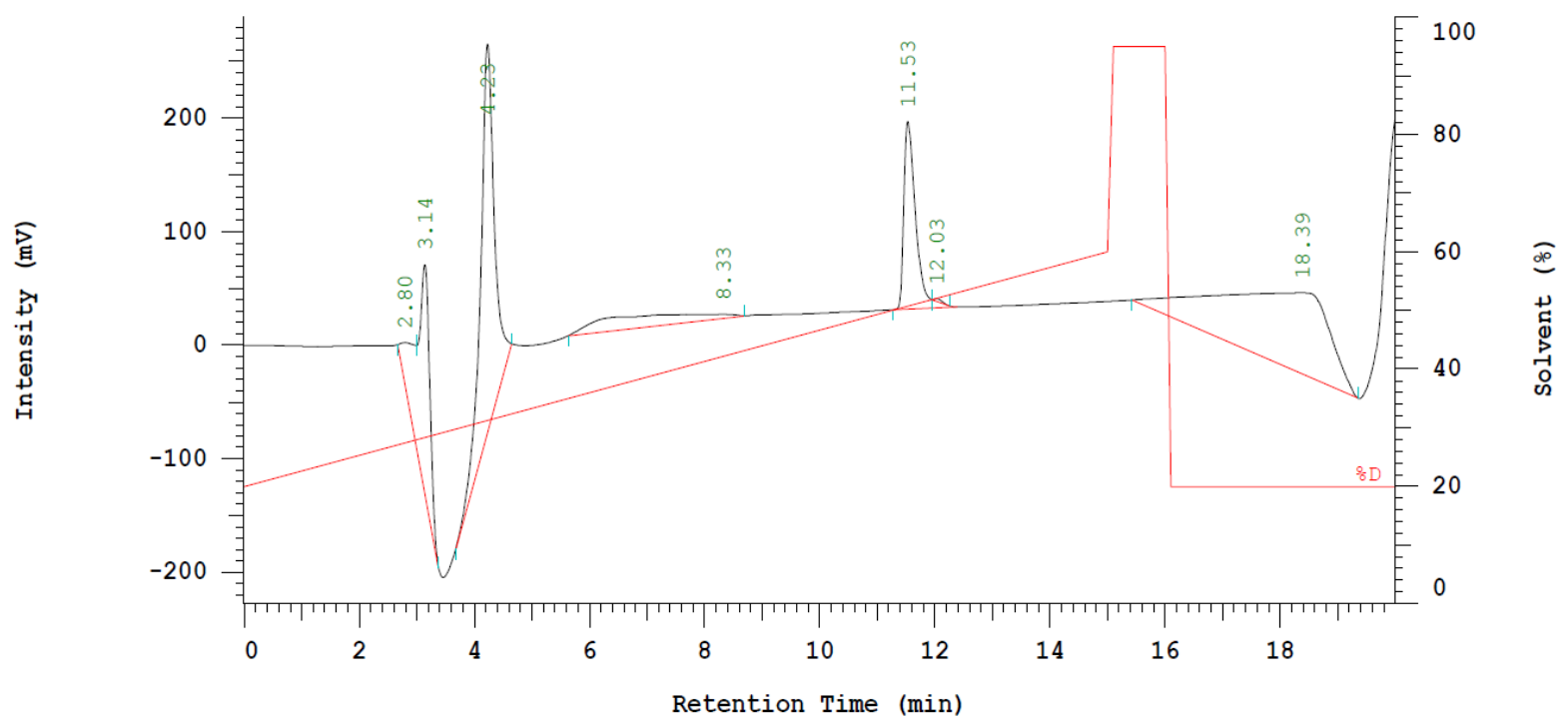

Figure S13: analytical HPLC chromatogram of purified Multi-TZMG 86, $\mathrm{t}_{\mathrm{r}}=11.53 \mathrm{~min}, 20-60 \% \mathrm{~A}$ in B over 15 min.

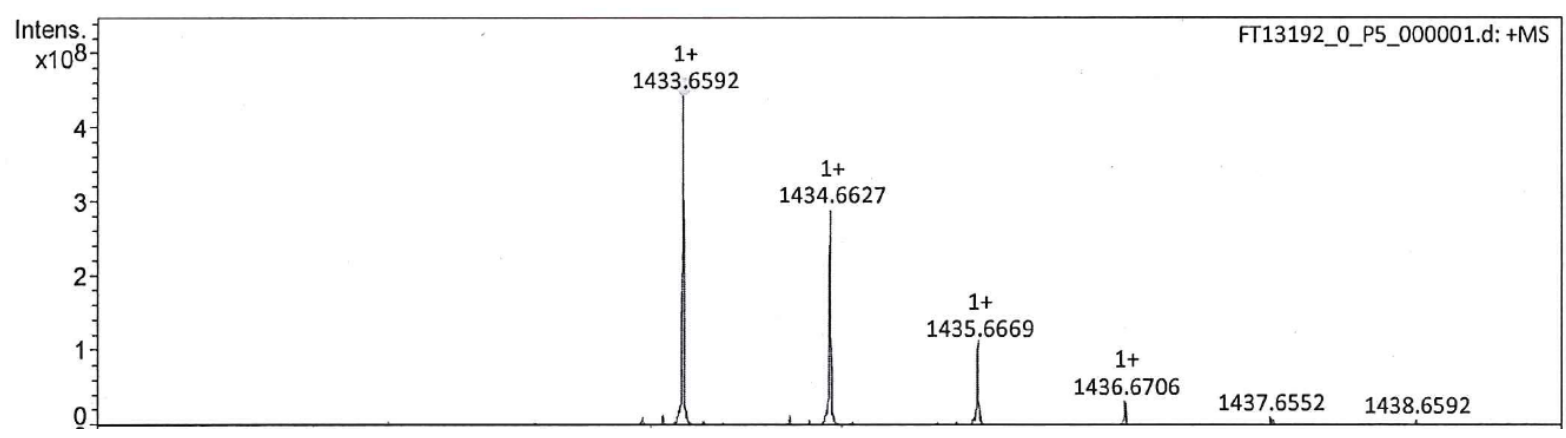

Figure S14: ESI HR-MS of purified Multi-TZMG 86. 
Multi-TZMG 87<smiles>CCCC[C@H](NC(=O)[C@H](Cc1c[nH]c2ccccc12)NC(=O)CNC(=O)[C@@H](Cc1ccc(O)cc1)n1cc([C@H](C)n2cc([C@@H](CCC(=O)O)NC(=O)CN3CCN(CC(=O)O)CCN(CC(=O)O)CCN(CC(=O)O)CC3)nn2)nn1)C(=O)N[C@@H](CC(=O)O)C(=O)N[C@@H](Cc1ccccc1)C(N)=O</smiles>

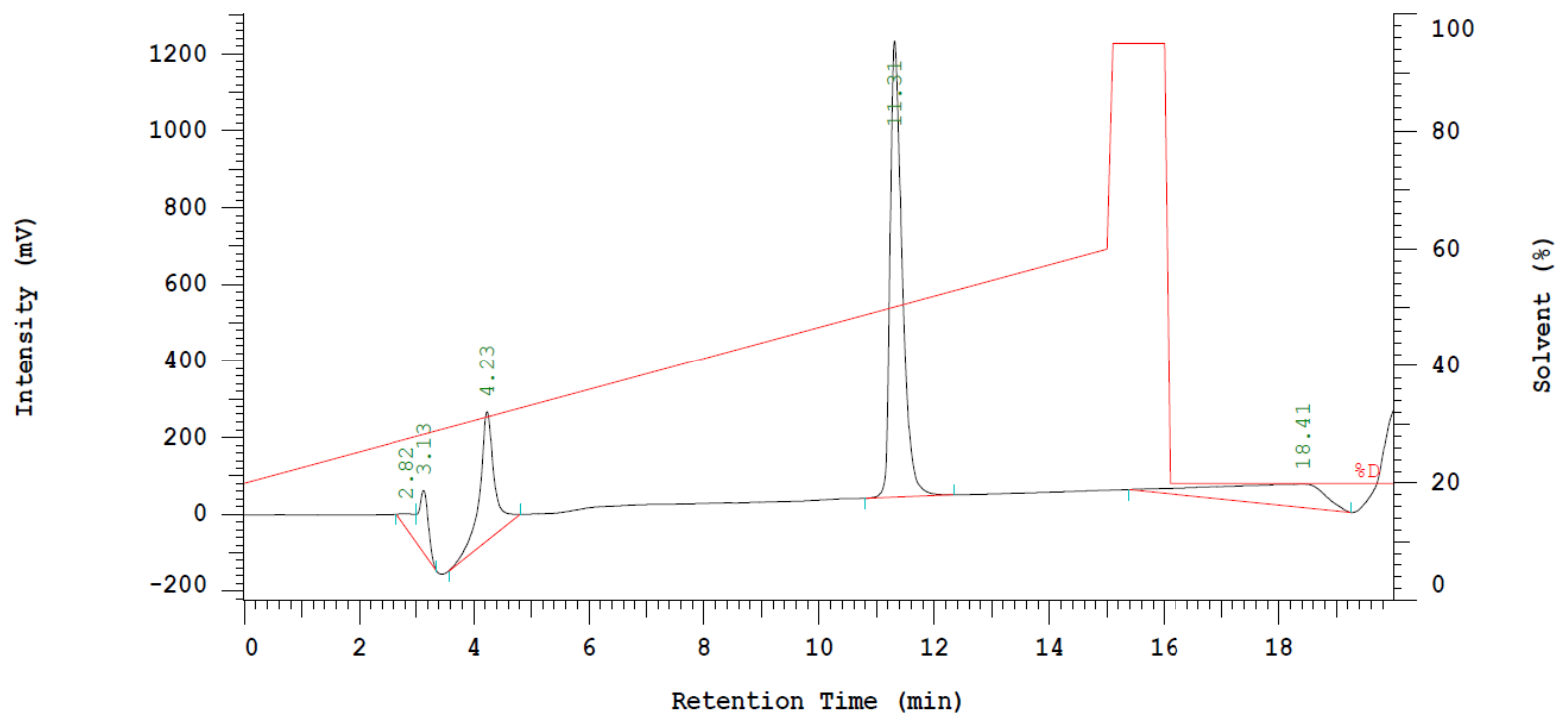

Figure S15: analytical HPLC chromatogram of purified Multi-TZMG 87, $\mathrm{t}_{\mathrm{r}}=11.31 \mathrm{~min}, 20-60 \%$ A in B over 15 min.

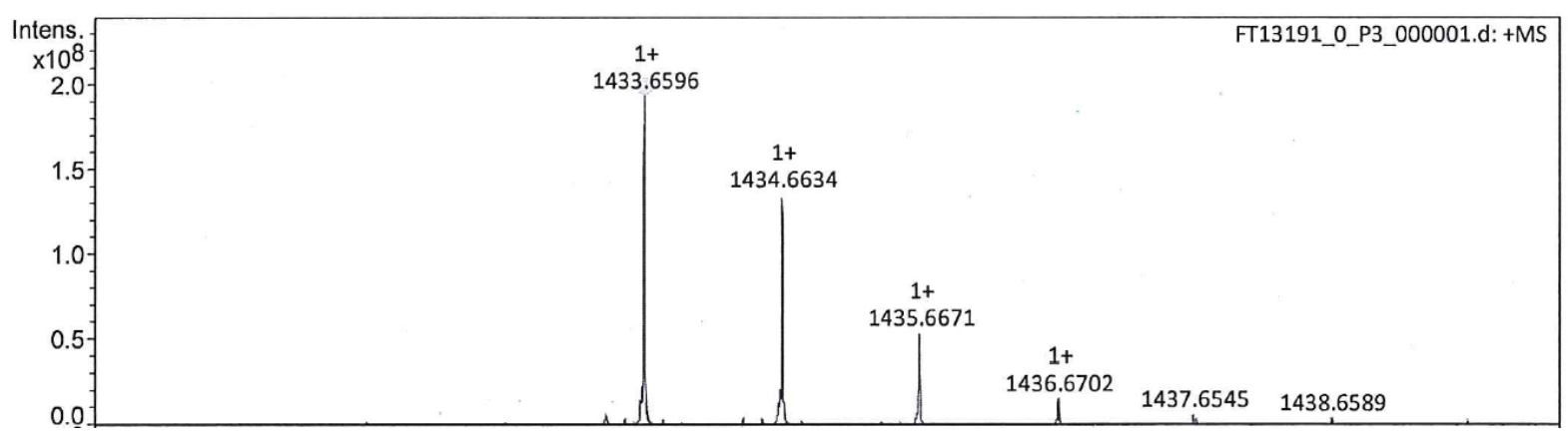

Figure S16: ESI HR-MS of purified Multi-TZMG 87. 
Multi-TZMG 876<smiles>CCCC[C@H](NC(=O)[C@H](Cc1c[nH]c2ccccc12)NC(=O)Cn1cc([C@H](Cc2ccc(O)cc2)n2cc([C@H](C)n3cc([C@@H](CCC(=O)O)NC(=O)CN4CCN(CC(=O)O)CCN(CC(=O)O)CCN(CC(=O)O)CC4)nn3)nn2)nn1)C(=O)N[C@@H](CC(=O)O)C(=O)N[C@@H](Cc1ccccc1)C(N)=O</smiles>

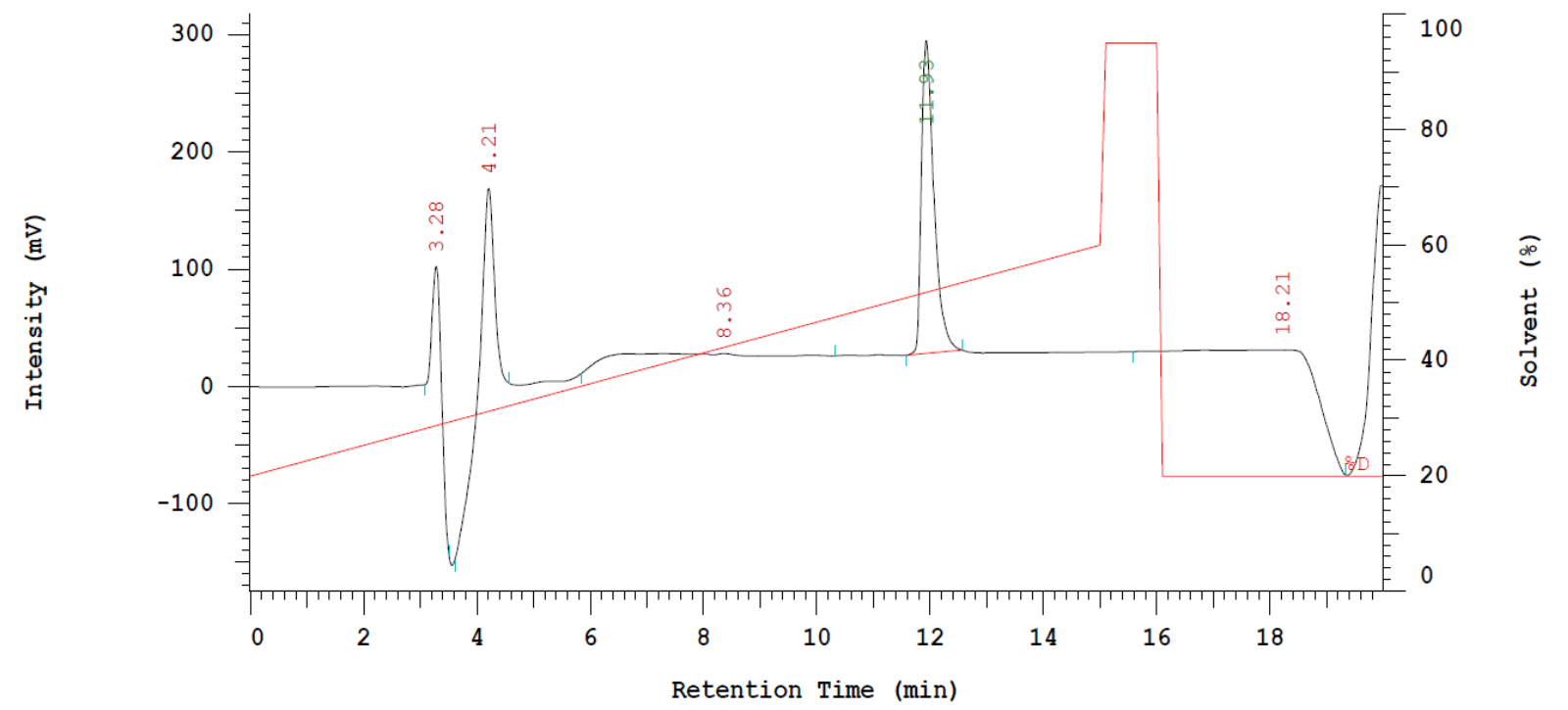

Figure S17: analytical HPLC chromatogram of purified Multi-TZMG 876, $\mathrm{t}_{\mathrm{r}}=11.93 \mathrm{~min}, 20-60 \%$ A in B over 15 min.

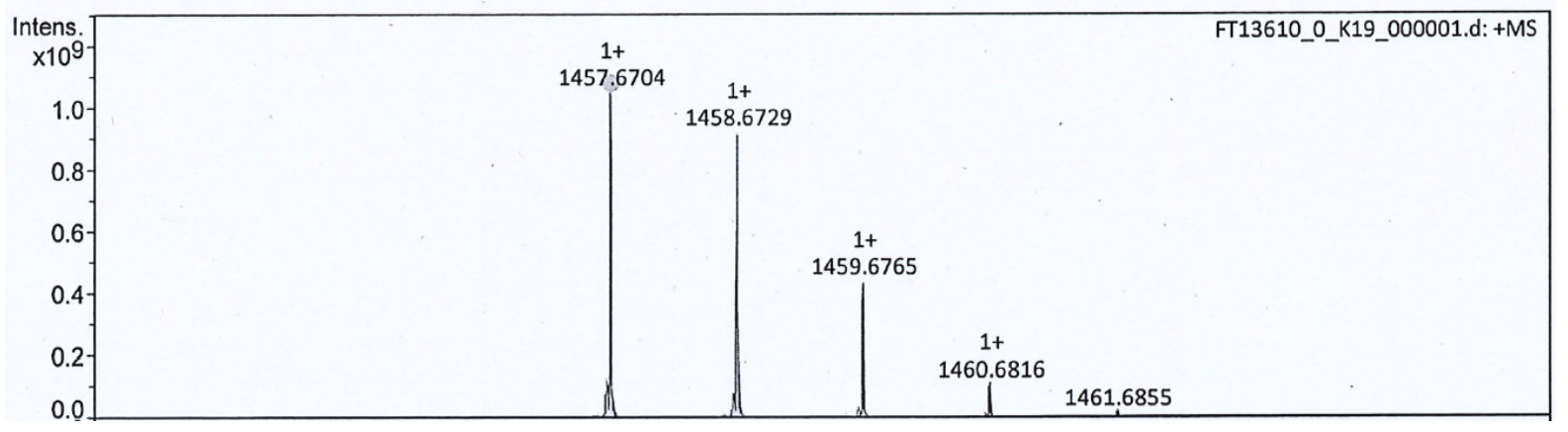

Figure S18: ESI HR-MS of purified Multi-TZMG 876. 


\section{4. $\gamma$-HPLC Chromatograms of Multi-TZMGs}

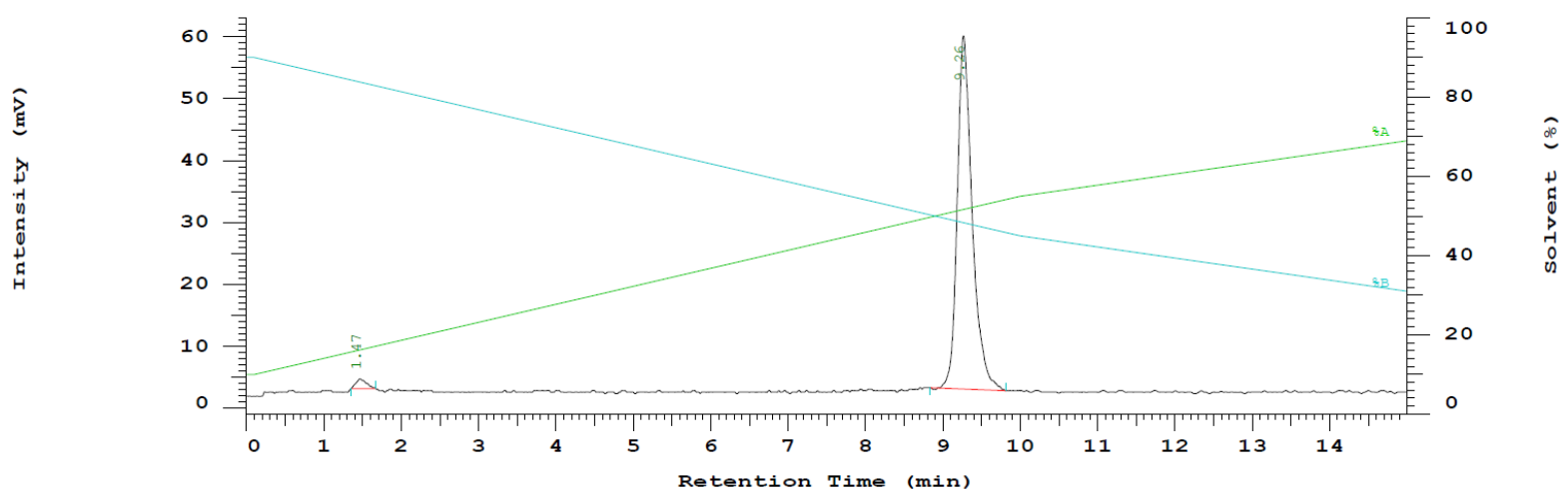

Figure S19: $\gamma$-HPLC chromatogram of [177Lu]Lu-TZMG 64, $\mathrm{t}_{\mathrm{r}}=9.26 \mathrm{~min}$.

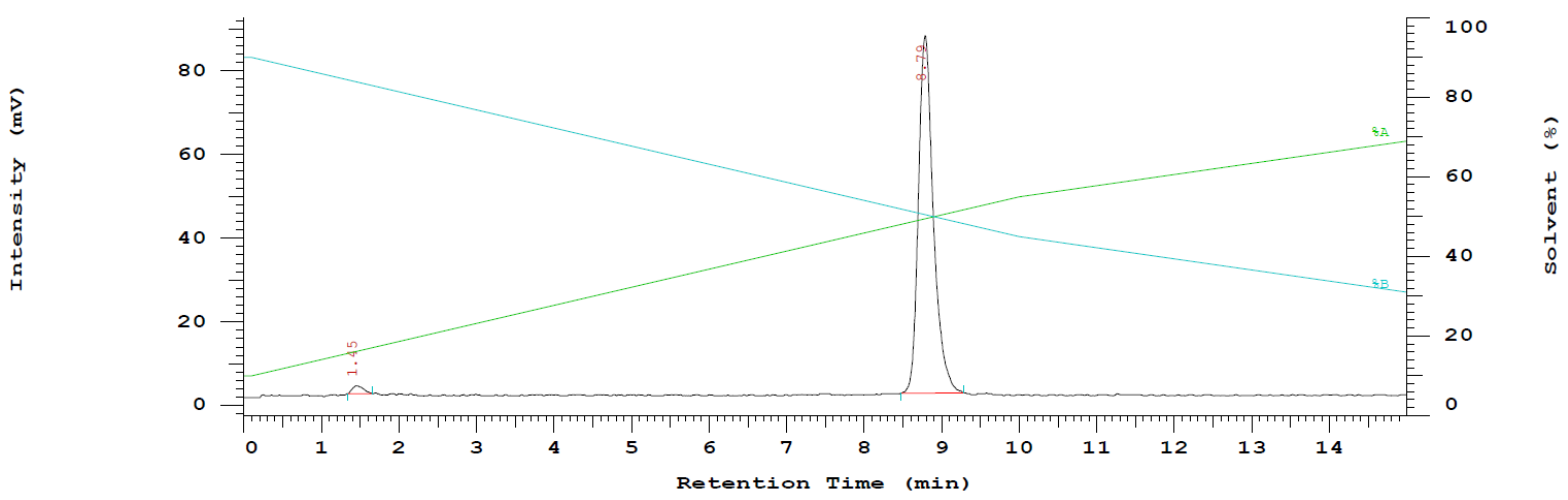

Figure S20: $\gamma$-HPLC chromatogram of $\left[{ }^{177} \mathrm{Lu}\right] \mathrm{Lu}-\mathrm{TZMG}$ 65, $\mathrm{t}_{\mathrm{r}}=8.79 \mathrm{~min}$.

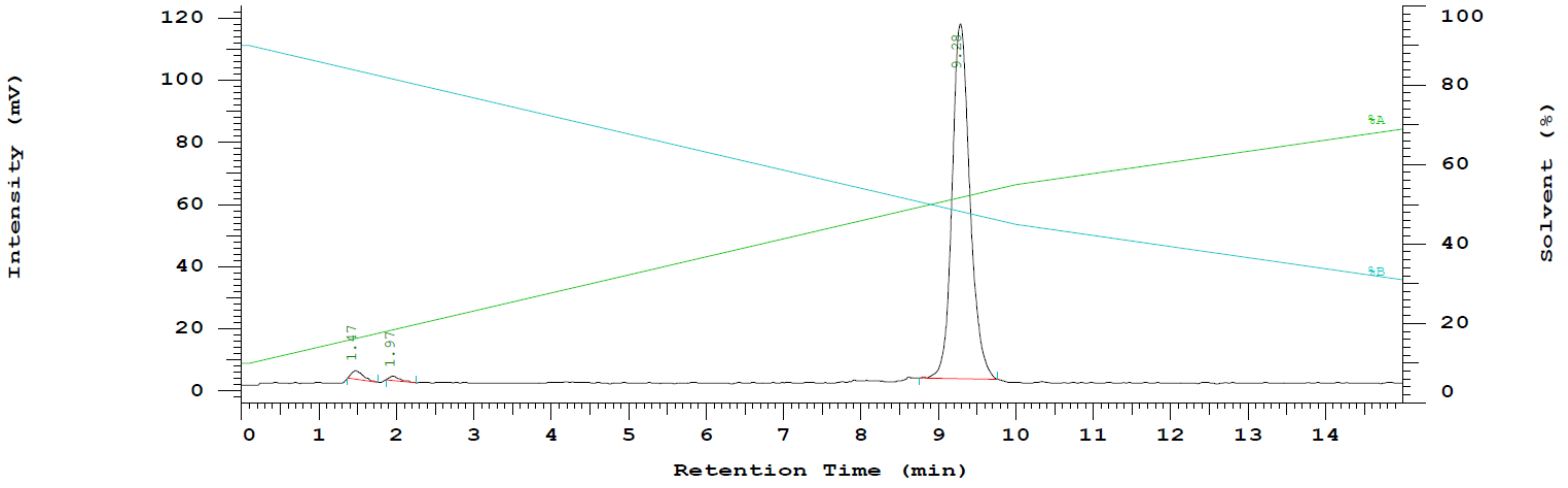

Figure S21: $\gamma$-HPLC chromatogram of [177Lu]Lu-TZMG 74, $\mathrm{t}_{\mathrm{r}}=9.28 \mathrm{~min}$. 


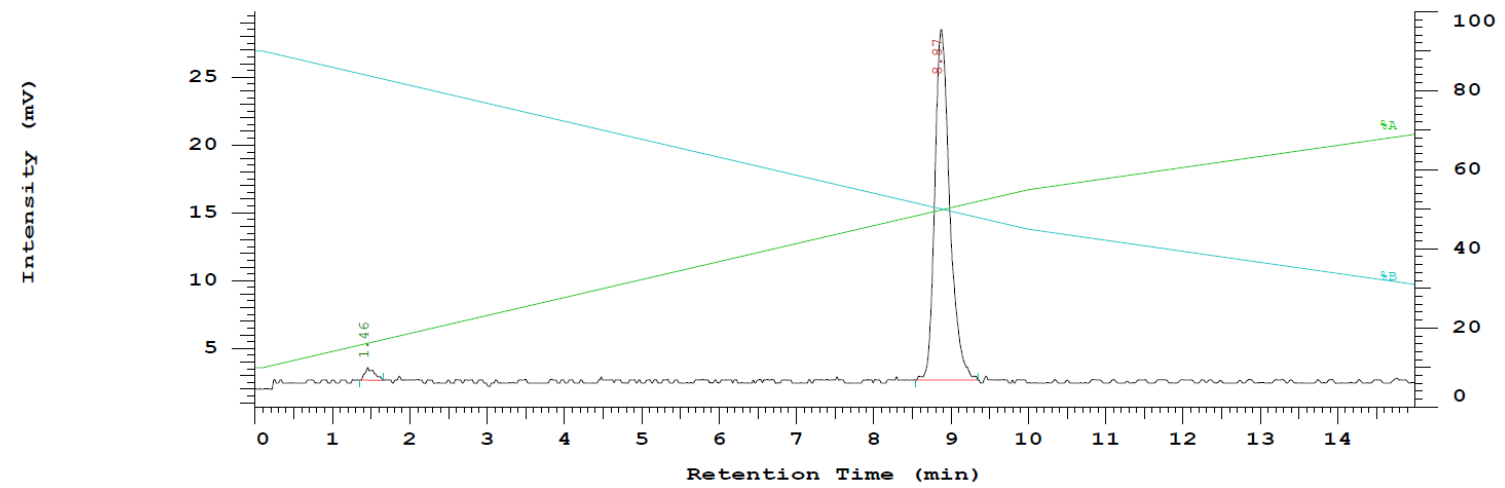

Figure S22: $\gamma$-HPLC chromatogram of $\left[{ }^{177} \mathrm{Lu}\right] \mathrm{Lu}-\mathrm{TZMG} \mathrm{76}, \mathrm{tr}_{\mathrm{r}}=8.87 \mathrm{~min}$.

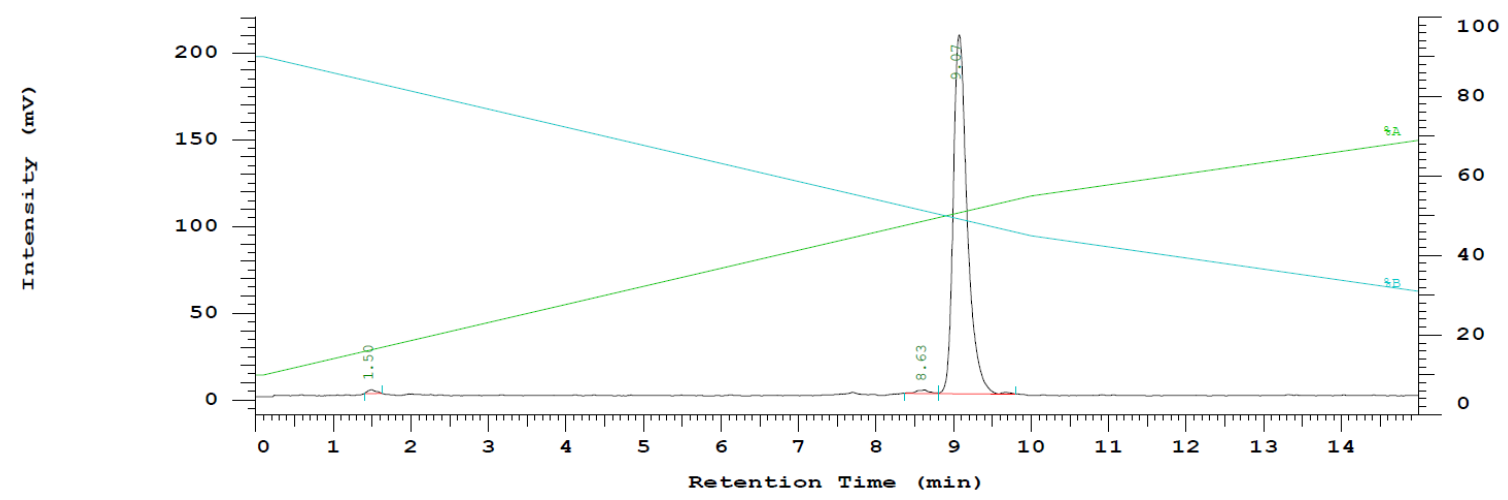

Figure S23: $\gamma$-HPLC chromatogram of $\left[{ }^{177 L u}\right] \mathrm{Lu}-\mathrm{TZMG} \mathbf{8 6}, \mathrm{t}_{\mathrm{r}}=9.07 \mathrm{~min}$

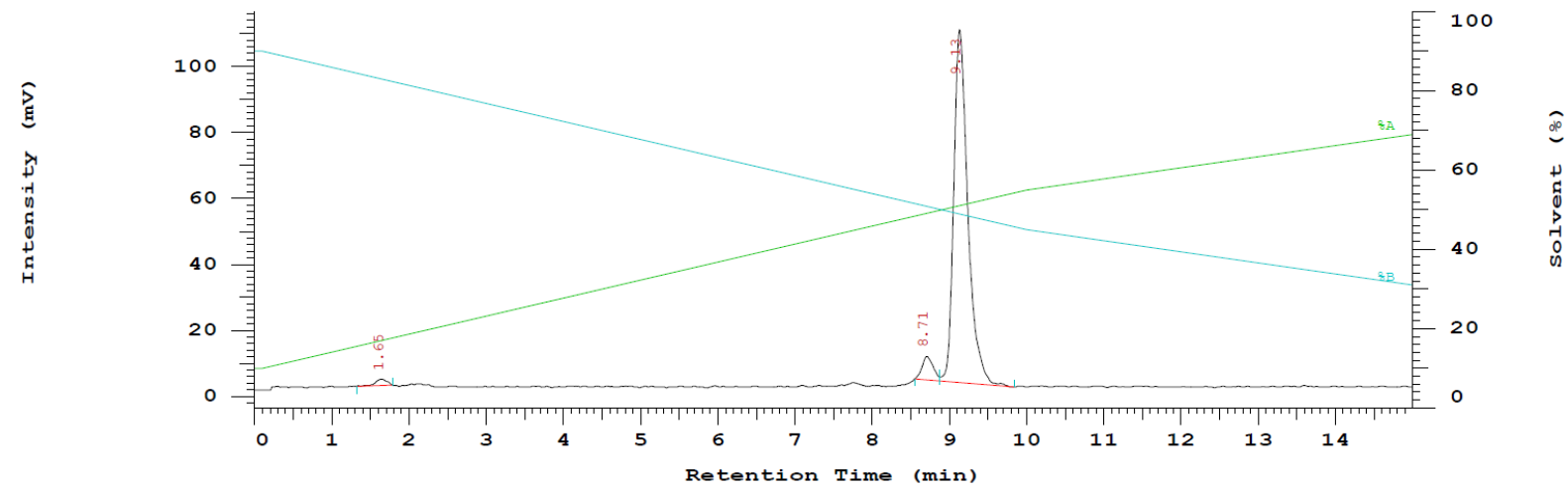

Figure S24: $\gamma$-HPLC chromatogram of $\left[{ }^{177} \mathrm{Lu}\right] \mathrm{Lu}-\mathrm{TZMG}$ 87, $\mathrm{t}_{\mathrm{r}}=9.13 \mathrm{~min}$

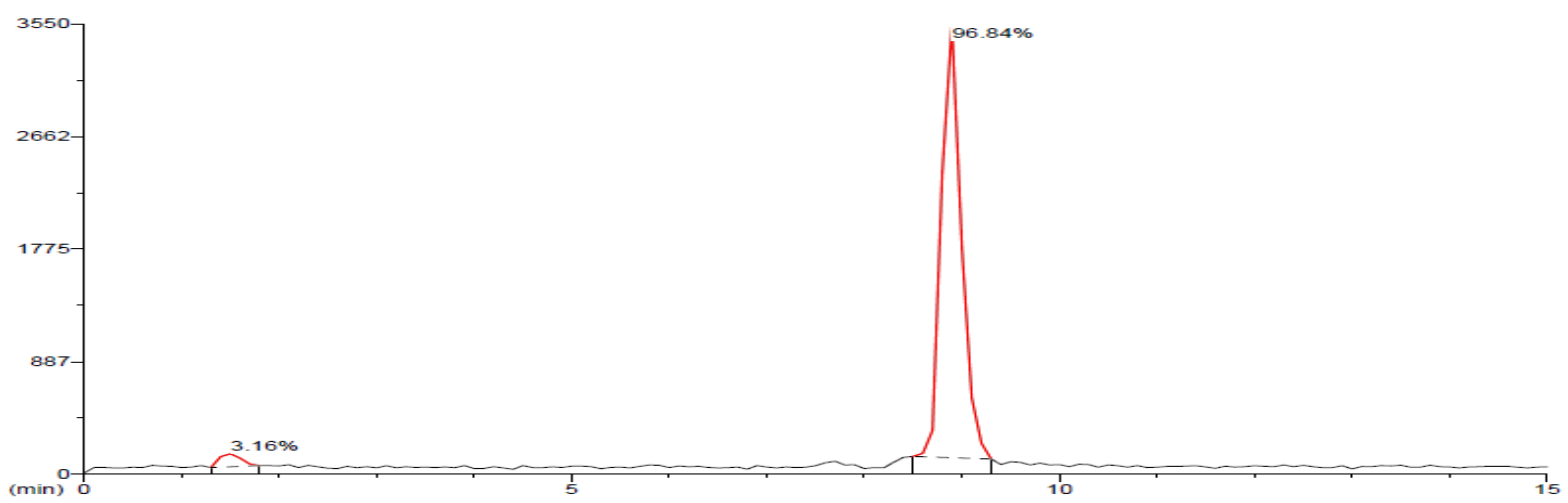

Figure S25: $\gamma$-HPLC chromatogram of [177Lu]Lu-TZMG 876, $\mathrm{t}_{\mathrm{r}}=8.90 \mathrm{~min}$ 


\section{Comparison of Mono- and Multi-TZMGs in vitro}

Graphs displaying cell internalization, competition binding and plasma degradation in vitro (from left to right) of multi-TZMGs (solid lines) with their respective two or three mono-TZMGs ${ }^{3}$ (dashed lines).
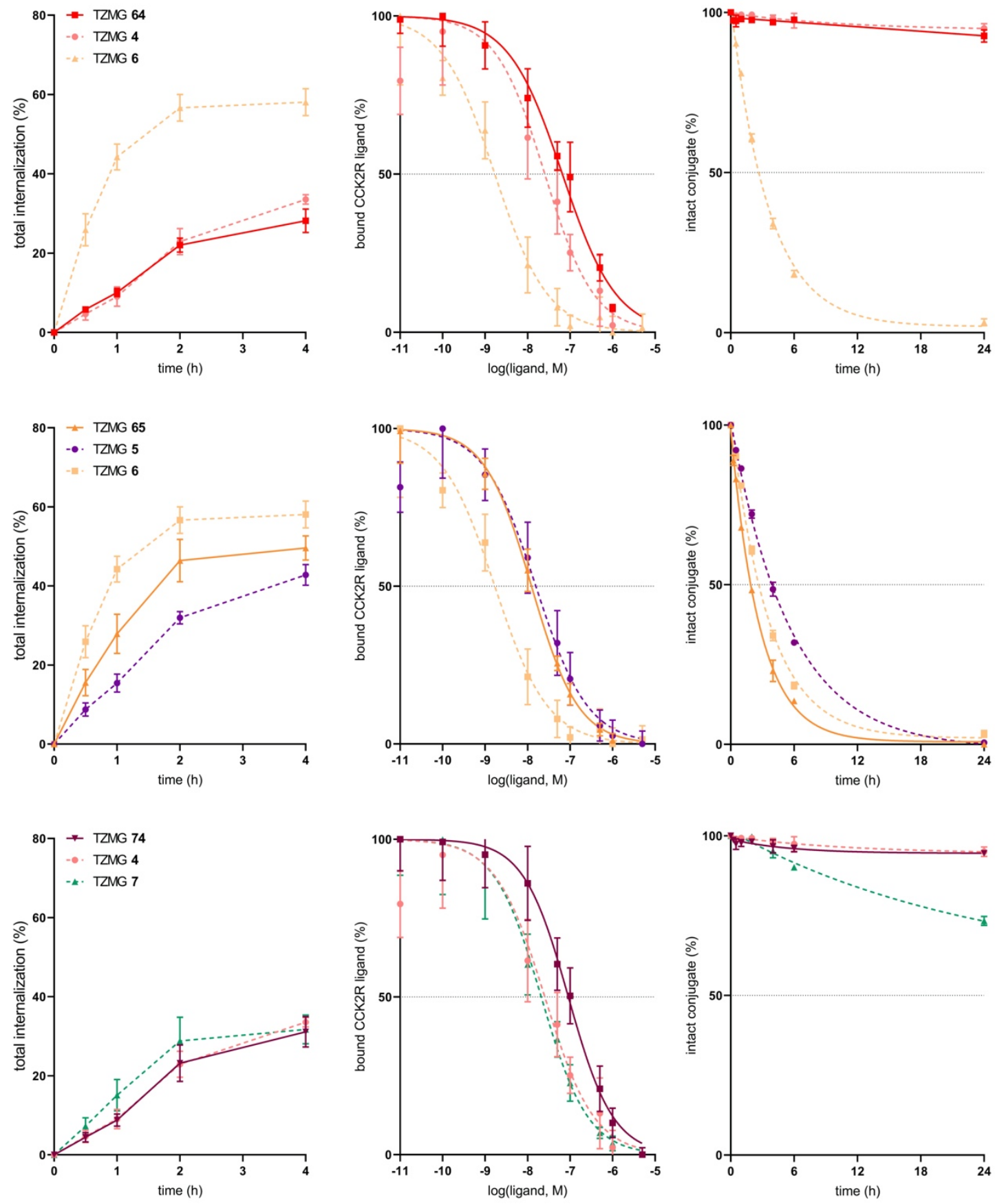

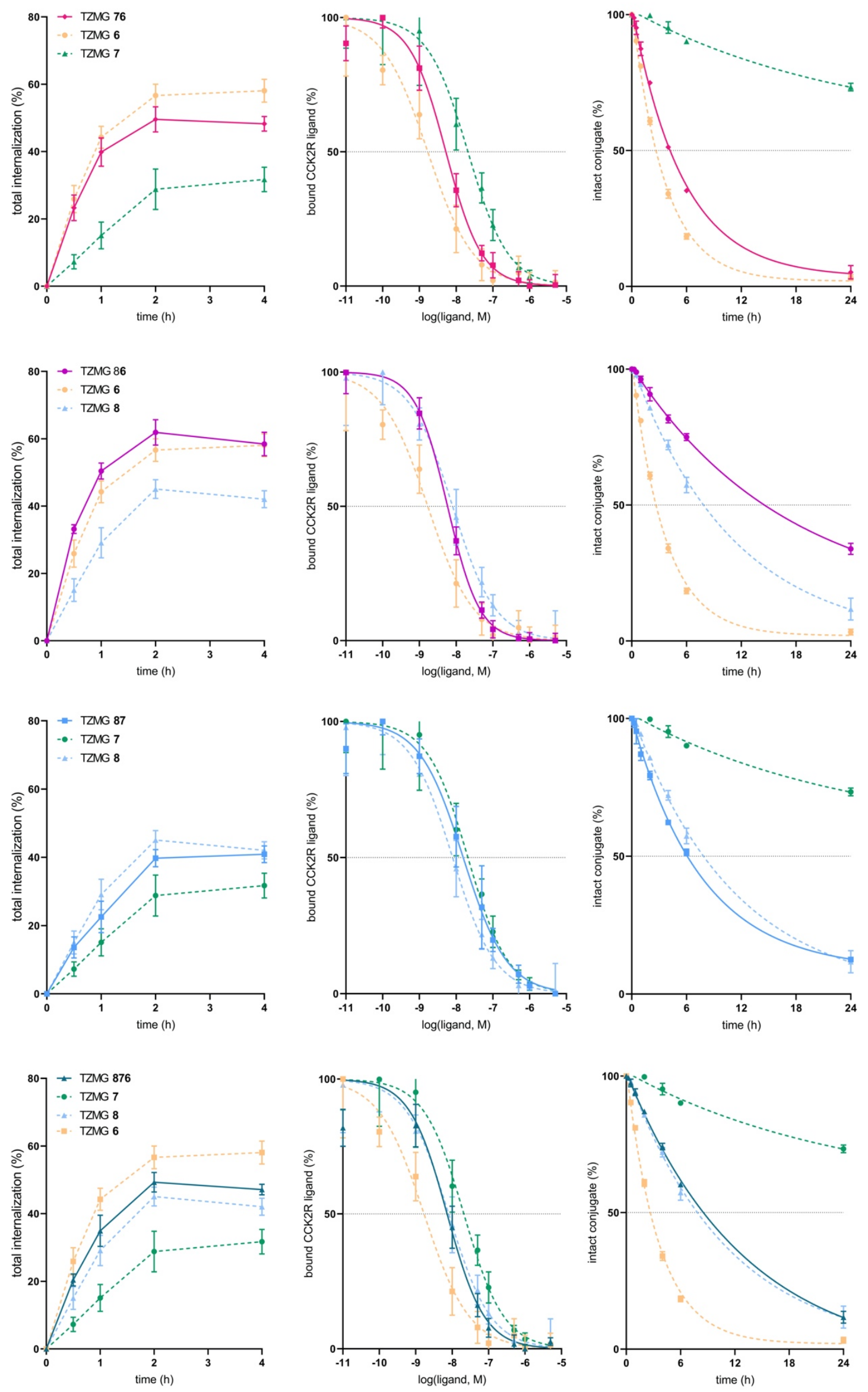


\section{Metabolic Profiles after $4 \mathrm{~h}$ of Incubation in Plasma}

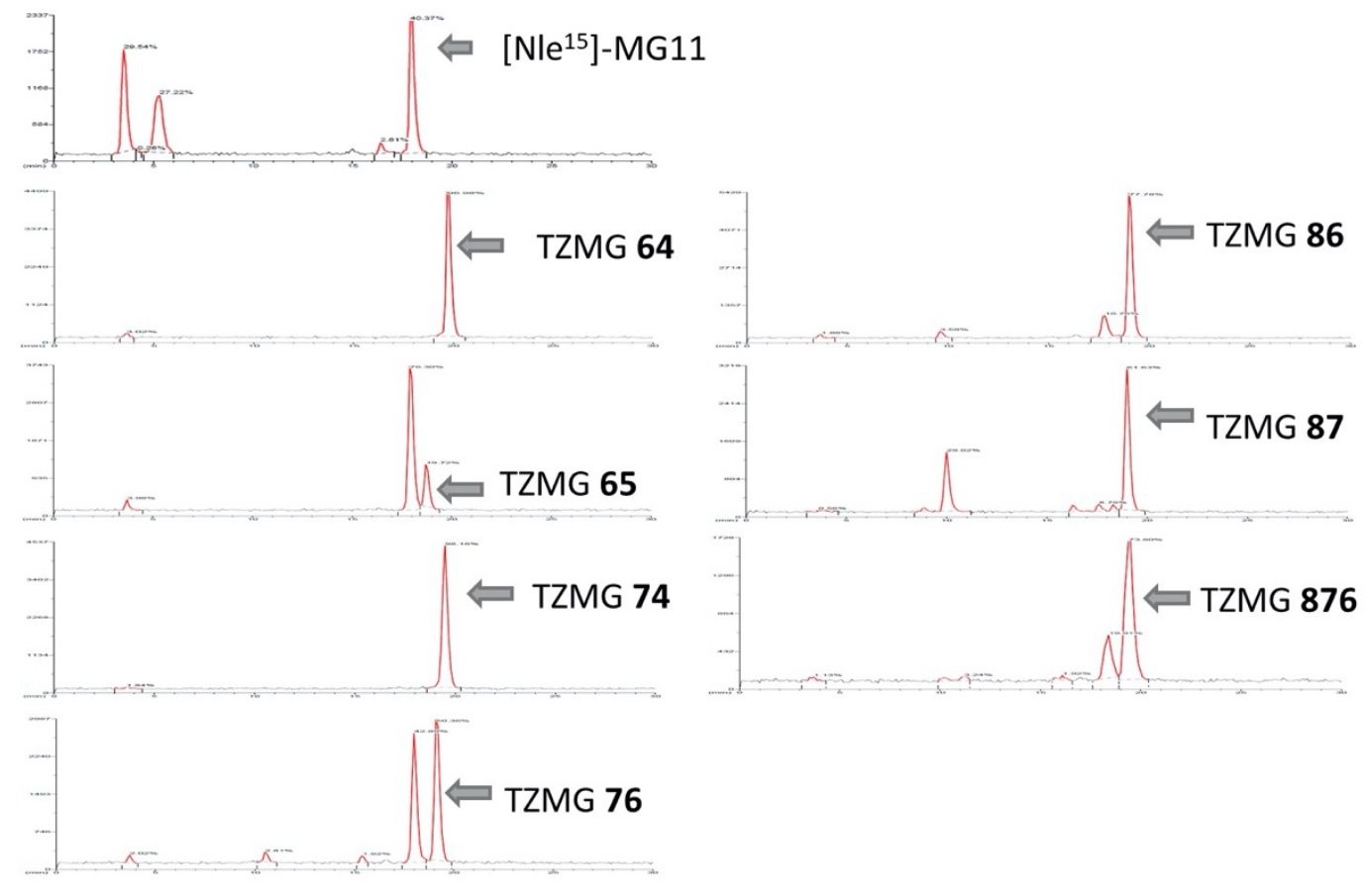

Figure S26: chromatograms of $\gamma$-HPLC showing metabolic profiles of [Nle15]MG11 and multi-TZMGs after $4 \mathrm{~h}$ of incubation in human blood plasma. Representative chromatograms were chosen.

\section{Internalization: Blocking Experiments}

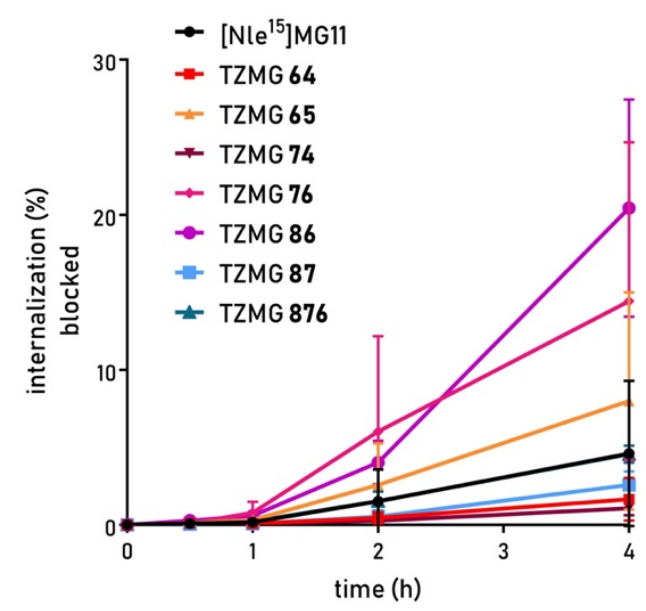

Figure S27: cell internalization of [177Lu]Lu-multi-TZMGs in presence of a 5000-fold molar excess of minigastrin over 4 h. Data points show mean \pm SD. $(n=3-5$ in triplicate)

Blocking experiments with excess of minigastrin reduced the uptake after $30 \mathrm{~min}, 1 \mathrm{~h}$, and $2 \mathrm{~h}$ of incubation, but were less effective after $4 \mathrm{~h}$ for multi-TZMGs $\mathbf{6 5}, \mathbf{7 6}$, and $\mathbf{8 6}$. This was already observed for mono-TZMG $6 .{ }^{3}$ It was hypothesized that the efficiency of the blocking agent is reduced for the highly affine novel ligands because of Met ${ }^{15}$ in minigastrin. Oxidation of Met to the corresponding sulfoxide due to incubation and exposure to oxygen leads to loss of affinity towards the CCK2 $\mathrm{R}^{4-6}$ and, as a consequence, no longer blocks the receptors efficiently for the highly affine 
ligands. To avoid oxidation side products during radiolabeling of the minigastrin analogs, Met 15 was replaced by $\mathrm{Nle}^{15}$ in all mono- and multi-TZMGs.

\section{Biodistribution: Tables of All Organs and Blocking Experiments}

Data of biodistribution studies 4 hours post injection are expressed as percentage of the injected radioactivity per gram of tissue (i.A./g). Blocking was performed by injection of a 6000 -fold excess of minigastrin. Entries represent mean \pm standard deviation ( $n=4$ mice per group).

Table S1: Biodistribution of reference compound [Nle15]MG11. Data of reference compound was previously reported and is listed here for comparison. ${ }^{3}$

\begin{tabular}{lcc|cc}
\hline [Nle ${ }^{15}$ ]MG11 & \multicolumn{2}{c|}{ total } & \multicolumn{2}{c}{ blocking } \\
& \% i.A./g & \pm SD & \% i.A./g & \pm SD \\
\hline Blood & 0.033 & 0.034 & 0.028 & 0.026 \\
Heart & 0.033 & 0.024 & 0.028 & 0.017 \\
Lung & 0.057 & 0.038 & 0.080 & 0.105 \\
Spleen & 0.044 & 0.019 & 0.042 & 0.020 \\
Kidneys & 0.922 & 0.196 & 0.965 & 0.190 \\
Pancreas & 0.086 & 0.060 & 0.080 & 0.081 \\
Stomach & 0.809 & 0.423 & 0.093 & 0.069 \\
Intestines & 0.188 & 0.228 & 0.050 & 0.025 \\
Liver & 0.096 & 0.037 & 0.176 & 0.224 \\
Muscle & 0.018 & 0.010 & 0.021 & 0.008 \\
Bone & 0.112 & 0.079 & 0.123 & 0.072 \\
Tumor & 1.475 & 0.729 & 0.176 & 0.080 \\
\hline
\end{tabular}

Table S2: Biodistribution of reference TZMG 64

\begin{tabular}{lcc|cc}
\hline TZMG 64 & \multicolumn{2}{c|}{ total } & \multicolumn{2}{c}{ blocking } \\
& $\%$ i.A./g & \pm SD & \% i.A./g & \pm SD \\
\hline Blood & 0.203 & 0.013 & 0.243 & 0.103 \\
Heart & 0.098 & 0.010 & 0.120 & 0.039 \\
Lung & 0.160 & 0.014 & 0.158 & 0.084 \\
Spleen & 0.058 & 0.010 & 0.078 & 0.022 \\
Kidneys & 0.555 & 0.079 & 0.860 & 0.275 \\
Pancreas & 0.068 & 0.005 & 0.068 & 0.022 \\
Stomach & 0.585 & 0.138 & 0.280 & 0.090 \\
Intestines & 0.205 & 0.127 & 0.230 & 0.111 \\
Liver & 0.128 & 0.005 & 0.253 & 0.152 \\
Muscle & 0.028 & 0.010 & 0.035 & 0.017 \\
Bone & 0.075 & 0.013 & 0.098 & 0.053 \\
Tumor & 2.025 & 1.044 & 0.689 & 0.335 \\
\hline
\end{tabular}


Table S3: Biodistribution of reference TZMG 65.

\begin{tabular}{lcc|cc}
\hline TZMG 65 & \multicolumn{2}{c|}{ total } & \multicolumn{2}{c}{ blocking } \\
& \% i.A./g & \pm SD & \% i.A./g & \pm SD \\
\hline Blood & 0.533 & 0.091 & 0.383 & 0.133 \\
Heart & 0.198 & 0.036 & 0.143 & 0.050 \\
Lung & 0.380 & 0.095 & 0.273 & 0.080 \\
Spleen & 0.120 & 0.016 & 0.100 & 0.026 \\
Kidneys & 0.915 & 0.100 & 0.897 & 0.040 \\
Pancreas & 0.157 & 0.060 & 0.107 & 0.040 \\
Stomach & 1.165 & 0.304 & 0.210 & 0.046 \\
Intestines & 0.293 & 0.190 & 0.137 & 0.049 \\
Liver & 0.215 & 0.066 & 0.163 & 0.029 \\
Muscle & 0.143 & 0.119 & 0.070 & 0.010 \\
Bone & 0.450 & 0.457 & 0.150 & 0.026 \\
Tumor & 2.856 & 1.011 & 0.777 & 0.184 \\
\hline
\end{tabular}

Table S4: Biodistribution of reference TZMG 76

\begin{tabular}{lcc|cc}
\hline TZMG 76 & \multicolumn{2}{c|}{ total } & \multicolumn{2}{c}{ blocking } \\
& $\%$ i.A./g & \pm SD & \% i.A./g & \pm SD \\
\hline Blood & 0.080 & 0.100 & 0.025 & 0.013 \\
Heart & 0.043 & 0.026 & 0.030 & 0.014 \\
Lung & 0.075 & 0.013 & 0.125 & 0.144 \\
Spleen & 0.058 & 0.025 & 0.070 & 0.048 \\
Kidneys & 0.645 & 0.111 & 0.638 & 0.208 \\
Pancreas & 0.203 & 0.039 & 0.173 & 0.214 \\
Stomach & 1.295 & 0.044 & 0.215 & 0.091 \\
Intestines & 0.250 & 0.064 & 0.443 & 0.153 \\
Liver & 0.420 & 0.266 & 0.753 & 0.354 \\
Muscle & 0.035 & 0.010 & 0.043 & 0.022 \\
Bone & 0.313 & 0.255 & 0.758 & 0.904 \\
Tumor & 2.226 & 0.949 & 0.383 & 0.148 \\
\hline
\end{tabular}


Table S5: Biodistribution of reference TZMG 86.

\begin{tabular}{lcc|cc}
\hline TZMG 86 & \multicolumn{2}{c|}{ total } & \multicolumn{2}{c}{ blocking } \\
& \% i.A./g & \pm SD & \% i.A./g & \pm SD \\
\hline Blood & 0.018 & 0.005 & 0.010 & 0.000 \\
Heart & 0.018 & 0.005 & 0.018 & 0.005 \\
Lung & 0.068 & 0.022 & 0.050 & 0.008 \\
Spleen & 0.033 & 0.010 & 0.038 & 0.005 \\
Kidneys & 0.468 & 0.088 & 0.458 & 0.064 \\
Pancreas & 0.153 & 0.059 & 0.123 & 0.036 \\
Stomach & 1.230 & 0.286 & 0.500 & 0.087 \\
Intestines & 0.088 & 0.042 & 0.168 & 0.061 \\
Liver & 0.088 & 0.057 & 0.313 & 0.249 \\
Muscle & 0.010 & 0.000 & 0.020 & 0.020 \\
Bone & 0.050 & 0.022 & 0.038 & 0.015 \\
Tumor & 5.968 & 0.902 & 1.170 & 0.209 \\
\hline
\end{tabular}

Table S6: Biodistribution of reference TZMG 87.

\begin{tabular}{lcc|cc}
\hline TZMG 87 & \multicolumn{2}{c|}{ total } & \multicolumn{2}{c}{ blocking } \\
& $\%$ i.A./g & \pm SD & \% i.A./g & \pm SD \\
\hline Blood & 0.005 & 0.006 & 0.000 & 0.000 \\
Heart & 0.013 & 0.005 & 0.010 & 0.000 \\
Lung & 0.030 & 0.008 & 0.020 & 0.000 \\
Spleen & 0.028 & 0.005 & 0.028 & 0.005 \\
Kidneys & 0.698 & 0.107 & 0.693 & 0.059 \\
Pancreas & 0.198 & 0.136 & 0.038 & 0.010 \\
Stomach & 0.773 & 0.282 & 0.043 & 0.015 \\
Intestines & 0.080 & 0.008 & 0.068 & 0.024 \\
Liver & 0.080 & 0.054 & 0.075 & 0.033 \\
Muscle & 0.013 & 0.005 & 0.010 & 0.000 \\
Bone & 0.035 & 0.013 & 0.025 & 0.006 \\
Tumor & 2.193 & 0.553 & 0.150 & 0.044 \\
\hline
\end{tabular}


Table S7: Biodistribution of reference TZMG 876.

\begin{tabular}{lcc|cc}
\hline TZMG 876 & \multicolumn{2}{c|}{ total } & \multicolumn{2}{c}{ blocking } \\
& \% i.A./g & \pm SD & \% i.A./g & \pm SD \\
\hline Blood & 0.073 & 0.026 & 0.108 & 0.043 \\
Heart & 0.033 & 0.005 & 0.040 & 0.014 \\
Lung & 0.100 & 0.018 & 0.148 & 0.059 \\
Spleen & 0.058 & 0.025 & 0.043 & 0.015 \\
Kidneys & 0.365 & 0.108 & 0.475 & 0.090 \\
Pancreas & 0.140 & 0.048 & 0.090 & 0.057 \\
Stomach & 0.843 & 0.109 & 0.150 & 0.056 \\
Intestines & 0.197 & 0.095 & 0.423 & 0.200 \\
Liver & 0.330 & 0.267 & 0.760 & 0.460 \\
Muscle & 0.020 & 0.012 & 0.035 & 0.017 \\
Bone & 0.168 & 0.058 & 0.138 & 0.082 \\
Tumor & 6.044 & 1.951 & 0.426 & 0.099 \\
\hline
\end{tabular}

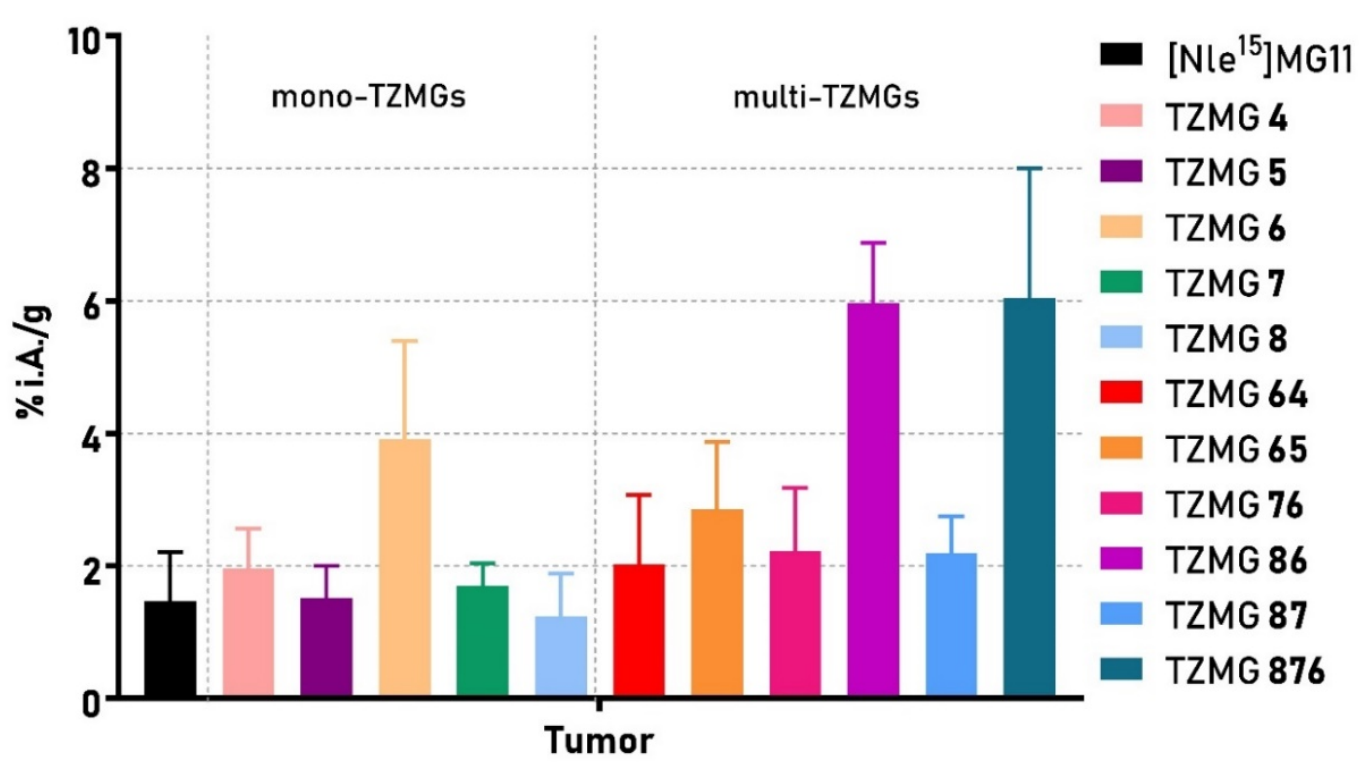

Figure S28: Uptake in tumor xenografts (\% i.A./g) of mono- and multi-TZMGs. Data of mono-TZMGs was reported previously ${ }^{3}$ and is listed here for comparison. (n= 4 animals per group )

\section{Tumor-to-Nontumor Ratios}

Table S8: Selected ratios of \% i.A./g of tumor-to-nontumor tissues of animals without co-injection of excess of minigastrin. Entries as mean $\pm \mathrm{SD}(\mathrm{n}=4$ animals per group).

\begin{tabular}{lccccccc}
\hline Tumor-to- & [Nle15]MG11 & TZMG 64 & TZMG 65 & TZMG 76 & TZMG 86 & TZMG 87 & TZMG 876 \\
\hline Blood & $105.8 \pm 85.5$ & $10.1 \pm 3.8$ & $5.2 \pm 1.2$ & $59.4 \pm 47.1$ & $375 \pm 161$ & $225 \pm 7.8$ & $88.0 \pm 25.6$ \\
Kidneys & $1.83 \pm 0.88$ & $3.6 \pm 0.79$ & $3.2 \pm 1.4$ & $3.7 \pm 2.2$ & $13.1 \pm 3.0$ & $3.2 \pm 0.89$ & $17.3 \pm 5.7$ \\
Stomach & $1.99 \pm 0.84$ & $3.5 \pm 0.92$ & $2.4 \pm 0.5$ & $1.7 \pm 0.8$ & $5.0 \pm 1.1$ & $3.2 \pm 1.3$ & $7.2 \pm 1.6$ \\
Muscle & $84.2 \pm 43.4$ & $84.5 \pm 4.5$ & $13.1 \pm 10.8$ & $68.5 \pm 33.5$ & $596 \pm 44.8$ & $190.4 \pm 55$ & $376 \pm 186$ \\
\hline
\end{tabular}




\section{0. $\log \mathrm{D}_{\mathrm{pH}} 7.4$}

Table S9: Mean values of $\operatorname{LogD}$ at pH $7.4 \pm$ standard deviation for the ${ }^{177} \mathrm{Lu}$-labeled conjugates.

\begin{tabular}{lc}
\hline tracer & $\log _{\mathbf{p H}} \mathbf{7 . 4}[\mathbf{m e a n} \pm \mathbf{S D}]$ \\
\hline Nle $\left.^{15}\right]_{M G 11^{\mathrm{a}}}$ & $-3.86 \pm 0.18$ \\
\hline TZMG 4 $^{\mathrm{a}}$ & $-3.98 \pm 0.43$ \\
\hline TZMG 5 $^{\mathrm{a}}$ & $-4.00 \pm 0.35$ \\
\hline TZMG 6 $^{\mathrm{a}}$ & $-4.06 \pm 0.11$ \\
\hline TZMG 7 & $-3.90 \pm 0.18$ \\
\hline TZMG 8 & $-3.98 \pm 0.45$ \\
\hline TZMG 64 & $-3.49 \pm 0.26$ \\
\hline TZMG 65 & $-3.70 \pm 0.19$ \\
\hline TZMG 74 & $-3.74 \pm 0.37$ \\
\hline TZMG 76 & $-3.83 \pm 0.22$ \\
\hline TZMG 86 & $-3.83 \pm 0.18$ \\
\hline TZMG 87 & $-3.86 \pm 0.22$ \\
\hline TZMG 876 & $-3.61 \pm 0.25$ \\
\hline
\end{tabular}

${ }^{a}$ Data for $\left[\mathrm{Nle}^{15}\right]$ MG11 and mono-TZMGs were reported previously and are listed for comparison. ${ }^{3}$

\section{Literature References}

1. Valverde, I. E.; Bauman, A.; Kluba, C. A.; Vomstein, S.; Walter, M. A.; Mindt, T. L., 1,2,3Triazoles as Amide Bond Mimics: Triazole Scan Yields Protease-Resistant Peptidomimetics for Tumor Targeting. Angew. Chem. Int. Ed. 2013, 52 (34), 8957-8960.

2. Mascarin, A.; Valverde, I. E.; Vomstein, S.; Mindt, T. L., 1,2,3-Triazole Stabilized NeurotensinBased Radiopeptidomimetics for Improved Tumor Targeting. Bioconjugate Chem. 2015, 26 (10), 2143-2152.

3. Grob, N. M.; Häussinger, D.; Deupi, X.; Schibli, R.; Behe, M.; Mindt, T. L., TriazoloPeptidomimetics: Novel Radiolabeled Minigastrin Analogues for Improved Tumor Targeting. J. Med. Chem. 2020, doi: 10.1021/10.1021/acs.jmedchem.9b01937.

4. Morley, J. S., Structure-Function Relationships in Gastrin-Like Peptides. Proc. R. Soc. London, Ser. $B$ 1968, 170 (1018), 97-111.

5. Good, S.; Walter, M.; Waser, B.; Wang, X.; Müller-Brand, J.; Béhé, M.; Reubi, J.-C.; Maecke, H., Macrocyclic Chelator-Coupled Gastrin-Based Radiopharmaceuticals for Targeting of Gastrin Receptor-Expressing Tumours. Eur. J. Nucl. Med. Mol. Imaging 2008, 35 (10), 1868-1877.

6. Breeman, W. A. P.; Fröberg, A. C.; de Blois, E.; van Gameren, A.; Melis, M.; de Jong, M.; Maina, T.; Nock, B. A.; Erion, J. L.; Mäcke, H. R.; Krenning, E. P., Optimised Labeling, Preclinical and Initial Clinical Aspects of CCK-2 Receptor-Targeting with 3 Radiolabeled Peptides. Nucl. Med. Biol. 2008, 35 (8), 839-849. 